\title{
IL-15 supports the generation of protective lung-resident memory CD4 T cells
}

\author{
TM Strutt ${ }^{1}$, K Dhume $^{1}$, CM Finn ${ }^{1}$, JH Hwang ${ }^{1}$, C Castonguay ${ }^{2}$, SL Swain ${ }^{2}$ and KK McKinstry ${ }^{1}$
}

Tissue-resident memory $T$ cells $\left(T_{\mathrm{RM}}\right)$ provide optimal defense at the sites of infection, but signals regulating their development are unclear, especially for CD4 Tcells. Here we identify two distinct pathways that lead to the generation of CD4 $T_{R M}$ in the lungs following influenza infection. The $T_{R M}$ are transcriptionally distinct from conventional memory CD4 $T$ cells and share a gene signature with CD8 $\mathrm{T}_{\mathrm{RM}}$. The $\mathrm{CD} 4 \mathrm{~T}_{\mathrm{RM}}$ are superior cytokine producers compared with conventional memory cells, can protect otherwise naive mice against a lethal influenza challenge, and display functional specialization by inducing enhanced inflammatory responses from dendritic cells compared with conventional memory cells. Finally, we demonstrate than an interleukin (IL)-2-dependent and a novel IL-2-independent but IL-15-dependent pathway support the generation of cohorts of lung $T_{\mathrm{RM}}$.

\section{INTRODUCTION}

Memory CD4 T cells provide strong protection against viruses through multiple pathways. They are especially important for clearing pathogens such as influenza A virus (IAV) against which neutralizing antibody $(\mathrm{Ab})$ alone cannot confer longterm immunity. ${ }^{1}$ Several CD4 memory subsets have been described based on phenotypic, functional, and migratory properties, ${ }^{2}$ and optimal protection often involves multiple specialized populations acting in concert. ${ }^{3}$ A challenge for developing T-cell-based vaccines is thus identifying the kinds of memory cells needed for optimal clearance of individual pathogens and elucidating the signals required for the generation of each particular subset.

Tissue-resident memory $\mathrm{T}$ cells $\left(\mathrm{T}_{\mathrm{RM}}\right)$ cells provide a first line of defense due to their location at the sites of infection and display distinct functional attributes vs. circulating memory subsets. ${ }^{2,4-6}$ CD8 $\mathrm{T}_{\mathrm{RM}}$ formation is complex and appears to differ between tissue sites and the pathogen or priming model employed. The generation of CD8 $\mathrm{T}_{\mathrm{RM}}$ primed by IAV, and in many other models, requires transforming growth factor (TGF)- $\beta$-mediated upregulation of CD103 (a subunit of $\alpha_{\mathrm{E}} \beta_{7}$ integrin). ${ }^{7-13}$ In contrast to CD8 $\mathrm{T}_{\mathrm{RM}}$, elevated CD103 expression is not usually observed on CD4 $\mathrm{T}_{\mathrm{RM}}$ in either animal models or in humans. ${ }^{14,15}$ Thus it is likely that distinct cytokine cues and perhaps other signals differentially regulate CD8 and CD4 $\mathrm{T}_{\mathrm{RM}}$ generation and maintenance.

We recently found that interleukin (IL)-2 signals to effector CD4 T cells between 5 and 7 days postinfection (dpi) with IAV are crucial to direct memory development. IL-2 signals enhance IL-7 receptor expression on CD4 T cells, thereby improving their access to IL-7, which is essential for the transition of effector cells into memory and for their survival thereafter. IL-2 also acts during this brief window of the CD4 T-cell response to downregulate pro-apoptotic molecules, especially Bim, to promote short-term survival of effectors and to thus enable a greater cohort of cells for memory development. ${ }^{16,17}$ Almost all memory CD4 $\mathrm{T}$ cells primed by IAV in the spleen and draining lymph node (dLN) are dependent upon the receipt of IL-2 signals, as is a subset in the lung. ${ }^{16}$ However, our studies also clearly indicate that a subset of memory cells in the lungs of IAV-primed mice, the primary site of infection, is IL-2 independent. $^{16}$

Here we investigate the distinct subsets of IAV-primed memory CD4 T cells found in the lung and the role of IL-2 and other cytokine signals in their generation. We find that $\mathrm{T}_{\mathrm{RM}}$ comprise the majority of these memory cells and, surprisingly, that they include both an IL-2-dependent and an IL-2independent subset. The IL-2-dependent and -independent CD4 $\mathrm{T}_{\mathrm{RM}}$ share a surface phenotype that is distinct from

${ }^{1}$ Division of Immunity and Pathogenesis, Burnett School of Biomedical Sciences, College of Medicine, University of Central Florida, Orlando, Florida, USA and ${ }^{2}$ Department of Pathology, University of Massachusetts Medical School, Worcester, Massachusetts, USA. Correspondence: KK McKinstry (kai.mckinstry@ucf.edu)

Received 14 April 2017; accepted 17 October 2017; published online 29 November 2017; doi:10.1038/mi.2017.101 
conventional memory CD4 $\mathrm{T}$ cells present in the lung and spleen and express a distinct transcriptional profile including preferential expression of many of the genes found to differentiate $\mathrm{CD} 8 \mathrm{~T}_{\mathrm{RM}}$ from circulating memory CD8 $\mathrm{T}$ cells. The CD4 $\mathrm{T}_{\mathrm{RM}}$ are characterized by enhanced cytokine production and an increased capacity to induce rapid inflammatory responses from dendritic cells (DCs) as compared with conventional memory cells of the same specificity. Most importantly, $\mathrm{CD} 4 \mathrm{~T}_{\mathrm{RM}}$ are potent mediators of protection against IAV upon transfer to unprimed mice. Finally, we demonstrate that direct IL-15 signals to CD4 T-cell effectors are required to generate the IL-2-independent $\mathrm{CD} 4 \mathrm{~T}_{\mathrm{RM}}$ subset but that continued IL-15 is not required for its long-term maintenance. Our studies thus indicate that viral infection generates functionally specialized CD4 $\mathrm{T}_{\mathrm{RM}}$ through distinct pathways, contributing to the heterogeneity of protective lung CD4 T-cell memory.

\section{RESULTS}

\section{IAV primes IL-2-dependent and -independent lung-restricted CD4 $\mathrm{T}_{\mathrm{RM}}$}

To investigate the role of IL-2 signaling in the generation of CD4 $\mathrm{T}_{\mathrm{RM}}$, we first transferred OT-II.Thy1.1 TcR Tg CD4 T cells to unprimed $\mathrm{B} 6$ mice and challenged with a low dose of A/PR8$\mathrm{OVA}_{\text {II }}$, recognized by the OT-II TcR. ${ }^{18}$ We transferred $1 \times 10^{6}$ cells, a minimal number required to reliably track donor responses into the memory phase in this model of IAV infection. We used donor cells that had been primed in the presence of IL-2 in vitro prior to transfer in order to provide the requisite early-acting IL-2 signal needed to generate optimal CD4 T-cell effector responses against IAV. ${ }^{16}$ Groups of mice were treated with an isotype control $\mathrm{Ab}$ or with IL-2neutralizing Abs from 1 to $7 \mathrm{dpi}$ to block conventional memory generation. ${ }^{16}$ This IL-2-blocking regime faithfully replicates key aspects of the response of $I 2^{-1-} \mathrm{CD} 4 \mathrm{~T}$ cells against IAV in the lung and secondary lymphoid organs. ${ }^{16}$ In agreement with our previous findings in a similar adoptive transfer model in $\mathrm{BALB} / \mathrm{c}$ hosts, ${ }^{16}$ peak effector expansion was equivalent in mice treated with IL-2-neutralizing or isotype $\mathrm{Ab}$ (not shown). However, IL-2 neutralization prevented virtually all donor cell recovery in the spleen and dLN by $28 \mathrm{dpi}$ but left a population of readily detectable IL-2-independent memory cells in the lungs (Figure 1a).

To determine whether the IL-2-dependent and -independent memory cells detected in the lungs are $\mathrm{T}_{\mathrm{RM}}$ or a subset of circulating memory cells, we administered fluorescent anti$\mathrm{CD} 4 \mathrm{Ab}$ intravenously (i.v.) to B6 hosts at $28 \mathrm{dpi}$ and analyzed labeling of donor cells in the lung after 3-5 min. This technique can readily discriminate blood-borne cells present in the circulation, which become labeled with the i.v. administered $\mathrm{Ab}$, vs. those cells that are tissue-localized and thus protected from Ab labeling. ${ }^{19}$ Roughly $80-90 \%$ of donor cells were not labeled (i.v. shielded $^{\text {) }}$ in mice treated with isotype control $\mathrm{Ab}$ (Figure 1b), in agreement with previous studies demonstrating that the majority of lung memory CD4 $\mathrm{T}$ cells primed by IAV are not accessible to the vasculature. ${ }^{20}$ Strikingly, all donor cells in mice treated with IL-2-neutralizing $\mathrm{Ab}$ are i.v. shielded $^{\text {. }}$ (Figure 1b). These i.v. ${ }^{\text {shielded }}$ donor cells in the lung fit criteria used to identify $\mathrm{T}_{\mathrm{RM}} \cdot{ }^{19}$ To determine whether the i.v. ${ }^{\text {shielded }}$ cells reside primarily in lung airways or the parenchyma, we separately analyzed donor cells recovered from the bronchial alveolar lavage or the lung proper. Few i.v..$^{\text {shielded }}$ donor cells were recovered by bronchiolar lavage (Figure 1c), indicating preferential parenchymal vs. airway location of the i.v. ${ }^{\text {shielded }}$ memory cells in mice treated with either IL-2-neutralizing or control Ab.

\section{Lung-resident memory cells express a $\mathrm{T}_{\mathrm{RM}}$-associated phenotype}

To define the relationship between the IL-2-dependent and independent i.v. ${ }^{\text {shielded }}$ memory cells primed by IAV and $T_{R M}$ described in other models, we analyzed key surface markers CD103, CD69, and CD127. We also compared the phenotypes of i.v. ${ }^{\text {sheilded }}$ memory cells in the lungs with those of i.v. labeled donor cells isolated from the lung. Although IAV-primed CD8 $\mathrm{T}_{\mathrm{RM}}$ express high levels of CD103, which is known to be TGF- $\beta$ dependent, ${ }^{13}, 21$ all CD4 memory cells in the lung, whether

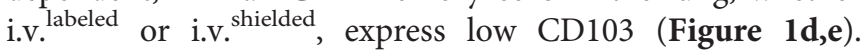
Furthermore, in separate experiments, we observed no change in donor cell recovery from the lungs at $28 \mathrm{dpi}$ in mice treated with either TGF- $\beta$-neutralizing $\mathrm{Ab}$ alone or with TGF- $\beta$-neutralizing $\mathrm{Ab}$ in conjunction with IL-2-neutralizing $\mathrm{Ab}$ from 1 to $7 \mathrm{dpi}$ (data not shown). These findings suggest that CD4 $\mathrm{T}_{\mathrm{RM}}$ develop through a pathway distinct from that supporting IAV-specific CD8 ${ }^{+} \mathrm{CD}_{103}{ }^{+}$TGF- $\beta$-dependent $\mathrm{T}_{\mathrm{RM}}$.

Most $\mathrm{T}_{\mathrm{RM}}$ express high surface $\mathrm{CD} 69$, which promotes tissue retention through repression of the sphingosine 1 phosphate receptor. ${ }^{22-24}$ The i.v. ${ }^{\text {shielded }}$ donor cells in mice treated with IL2-neutralizing or control $\mathrm{Ab}$ were uniformly $\mathrm{CD} 69^{\text {high }}$ compared with i.v. ${ }^{\text {labeled }}$ donors (Figure 1d,e). To determine whether increased CD69 expression by the i.v. ${ }^{\text {shielded }}$ memory cells is driven by recent TcR stimulation, we transferred OT-II cells from donor mice with green fluorescent protein (GFP) driven by the Nur77 protein locus $\left(\mathrm{Nr} 4 a 1^{\mathrm{eGFP}}\right)$ that express GFP transiently after antigen stimulation. ${ }^{17,25}$ We compared GFP signal from i.v. ${ }^{\text {labeled }}$ and

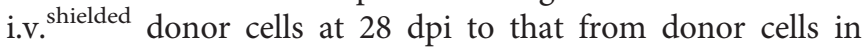
unprimed hosts. All donor cells expressed low, uniform levels of GFP (Figure 1f), indicating that continuing cognate TcR stimulation is not responsible for maintaining the CD69 expression on either the IL-2-dependent or -dependent i.v. ${ }^{\text {shielded }}$ cells, and arguing against a requirement for residual IAV antigen $\operatorname{depots}^{26}$ in sustaining the $\mathrm{CD}_{6} 9^{+}$ memory cells.

We also analyzed IL-7 receptor expression (CD127), which is upregulated on $\mathrm{CD} 4 \mathrm{~T}$ cells when they produce and respond to the autocrine IL-2 that facilitates effectors to transition to memory. ${ }^{16}$ Intriguingly, the i.v. ${ }^{\text {shielded }}$ memory cells in mice treated with either control or IL-2-neutralizing Abs expressed lower CD127 than did i.v. labeled memory cells (Figure 1d,e). This implies that the i.v. ${ }^{\text {shielded }}$ subset may be less dependent on 

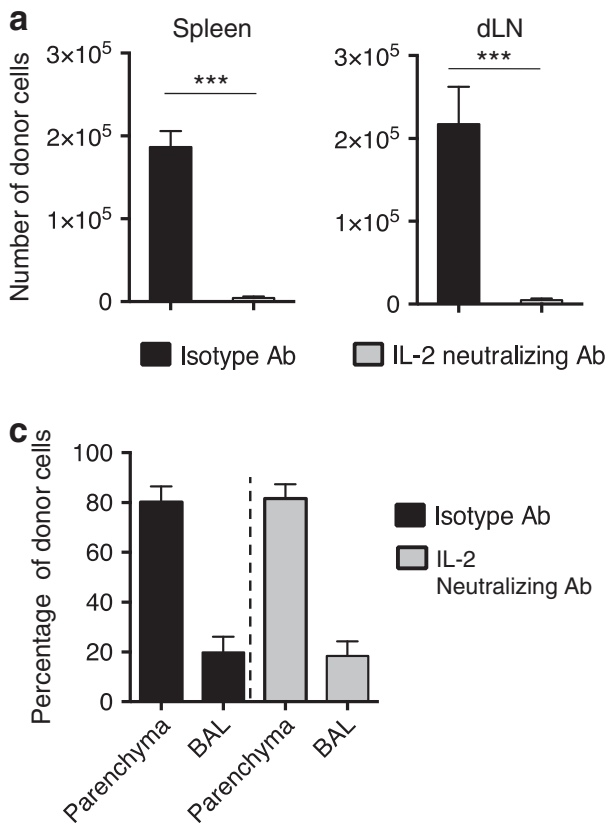

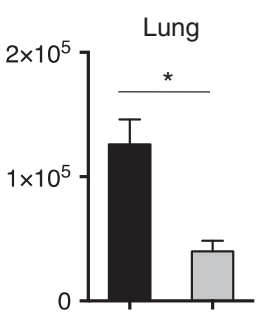

b

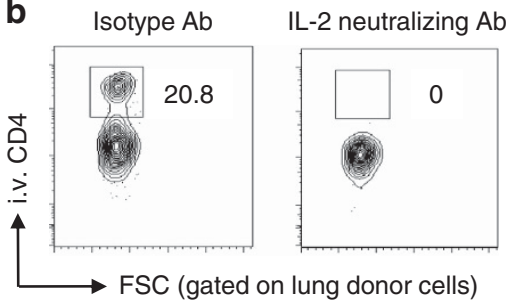

d

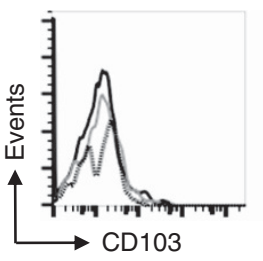

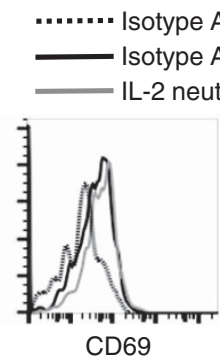

sotype Ab: i.v. labeled

sotype Ab: i.v. shielded

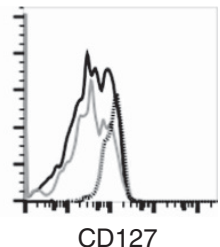

e
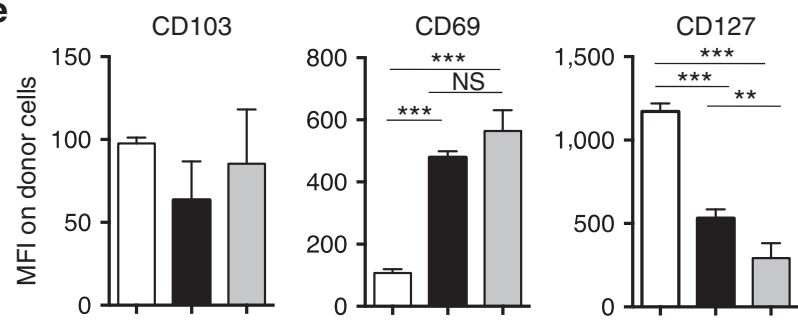

f
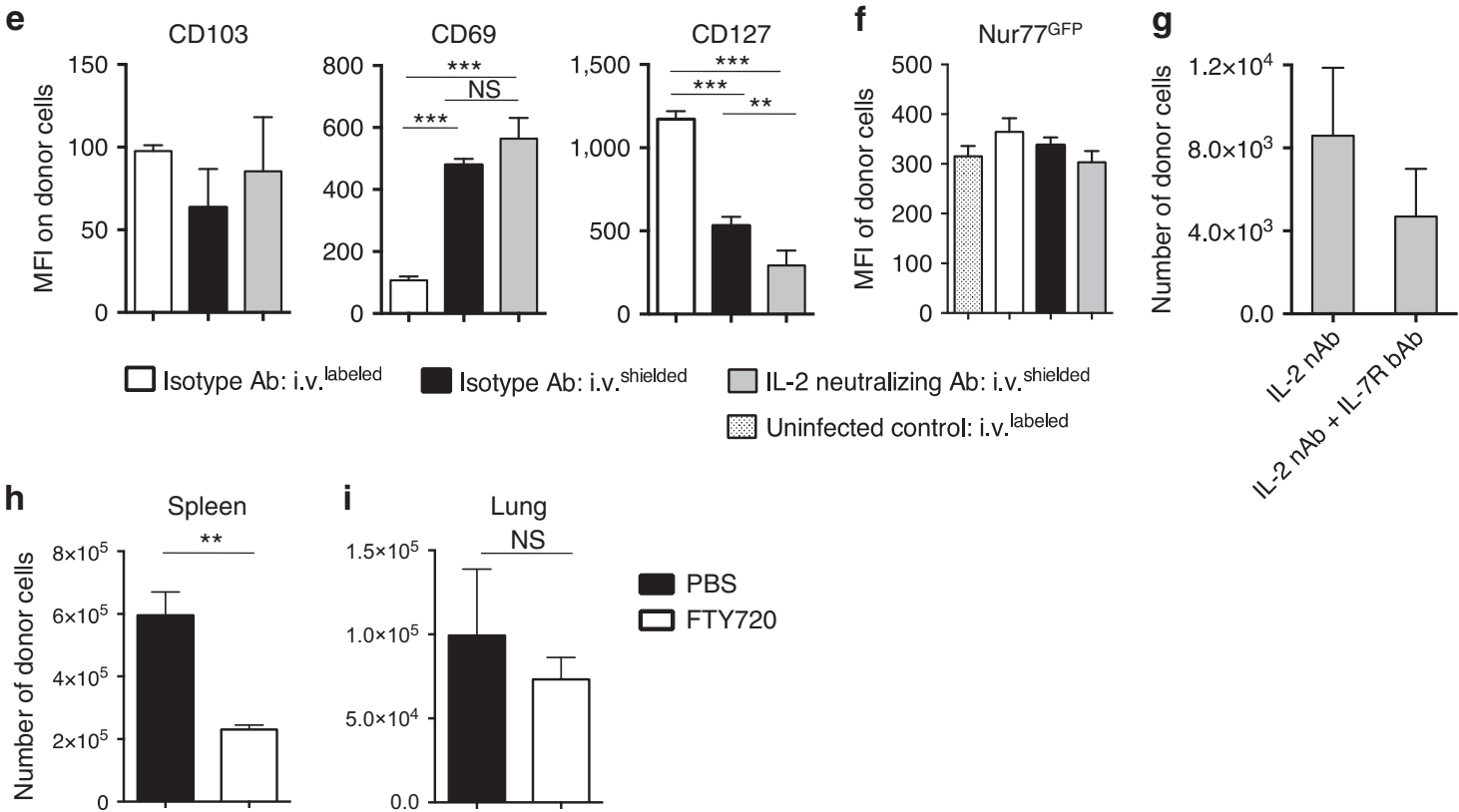

PBS

$\square$ FTY720

Figure 1 A tissue-resident memory T cell-associated phenotype is expressed by i.v. ${ }^{\text {shielded }}$ lung memory cells. Unprimed B6 mice received $1 \times 10^{6}$ congenic donor cells followed by priming with influenza $A$ virus (IAV) and treatment from 1 to $7 \mathrm{dpi}$ with interleukin (IL)-2-neutralizing antibodies (Abs) or isotype control $\mathrm{Ab}$. (a) Donor cells were enumerated at 28 days postinfection (dpi) in the stated organs (four mice per group; one of the three similar experiments). (b) At 28 dpi, recipient mice were injected intravenously (i.v.) with fluorescent Ab specific for CD4 and the frequency of donor cells stained (i.v. labeled) or not (i.v. ${ }^{\text {shielded }}$ ) was determined (representative staining). (c) The percentage of donor cells at 28 dpi recovered either in the bronchial alveolar lavage (BAL) or from the lung parenchyma (three mice per group; one of the two experiments). (d) Representative staining and (e) mean fluorescence intensity (MFI) analysis for donor cell for CD103, CD69, and CD127. (f) Nur77 GFP OT-II donors were analyzed for green fluorescent protein expression at 28 dpi discriminated based on their ability to be labeled by i.v. administered CD4 Ab (three mice per group; one of the two experiments). (g) Mice receiving donor cells were treated with IL-2-neutralizing Ab (IL-2n Ab) from 1 to $7 \mathrm{dpi}$, followed by treatment with phosphate-buffered saline (PBS) or with IL-7 receptor blocking Ab every other day from 10 to $26 \mathrm{dpi}$. The number of donor cells recovered from the lungs at $28 \mathrm{dpi}$ is shown (four mice per group; one of the two experiments). Mice receiving donor cells and IAV priming were treated or not with FTY720 for 5 consecutive days beginning on 23 dpi. On $28 \mathrm{dpi}$, (h) spleens and (i) lungs were analyzed for total donor cells (three mice per group; one of the two experiments). dLN, draining lymph node; FSC, forward scatter; NS, not significant.

IL-7 survival signals compared with conventional memory CD4 T cells. ${ }^{27}$ To test this, mice receiving donor cells and IL-2neutralizing Ab were also treated with an IL-7 receptor blocking $\mathrm{Ab}$ starting at $14 \mathrm{dpi}$ (when the virus is cleared) using a regime that in our previous studies reduced recovery of conventional CD4 memory cells primed by IAV by at least one log in the spleen and dLN and to a lesser but significant degree in the lung. ${ }^{16}$ IL-7 receptor blockade did not significantly reduce the 
recovery of the IL-2-independent lung memory cells (Figure 1g), which suggests that alternative survival factors

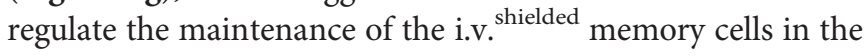
lung.

Finally, we sought to confirm that the i.v. shielded $^{\text {donor cells }}$ reside in the lung long term rather than representing a transient subpopulation of circulating cells. We thus treated IAV-primed mice that had received donor cells with FTY720, which blocks egress from the lymph nodes and results in a dramatic loss of circulating $\mathrm{T}$ cells after short-term treatment. ${ }^{28}$ Treatment for 5 days beginning at 23 dpi reduced the number of donor cells detected in the spleen by about threefold (Figure 1h) but had no impact on the number of donor cells detected in the lungs (Figure 1i), indicating that the i.v. ${ }^{\text {shielded }}$ memory population in the lung is distinct from the circulating lymphocyte pool.

Together, these results support the hypothesis that, after their initial priming, two distinct pathways, one IL-2 dependent and another that is IL-2 independent, support the generation of CD4 $T_{R M}$ in the lung. The fact that $T_{R M}$ generated in the presence and absence of IL-2 signaling share a common location and $\mathrm{CD} 103^{\text {low }} \mathrm{CD} 69^{\text {high }}$ phenotype supports the hypothesis that alternate pathways exist to produce closely related subsets of $T_{R M}$ that are physiologically relevant.

\section{A conserved $\mathrm{T}_{\mathrm{RM}}$ molecular signature}

CD8 $\mathrm{T}_{\mathrm{RM}}$ are distinguished from circulating CD8 memory cells in mice and humans by a unique gene expression signature. ${ }^{7,29,30}$ To determine whether differences in transcriptional regulation similarly distinguish $\mathrm{CD} 4 \mathrm{~T}_{\mathrm{RM}}$ and conventional memory cells primed by IAV, we performed whole-genome microarray analysis comparing sort-purified donor $T_{R M}$ (i.v. shielded $\mathrm{CD} 69^{\text {high }}$ ) from the lung mice against i.v. labeled

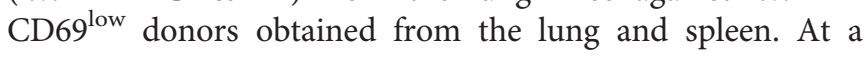
threshold of $>1.5$ and $P$-value of $0.05,79$ transcripts representing 69 known genes were identified as being differentially expressed between the $\mathrm{T}_{\mathrm{RM}}$ and conventional memory cells (Figure 2a and Supplementary Table SI online). Differential surface expression of four of these genes, Slamf6, Tnfs11 (RankL), Klrg1, and Cdh1(CD324), was validated by flow cytometry (Figure 2b,c). The 69 genes clustered into 6 significant DAVID functional annotation clusters with the most enriched being "cell adhesion" (Figure 2d and Supplementary Table SI).

We next compared the 69 genes distinguishing lung CD4 $\mathrm{T}_{\mathrm{RM}}$ with the transcriptional signatures of $\mathrm{CD} 103^{+} \mathrm{CD} 8 \mathrm{~T}_{\mathrm{RM}}$ isolated from various mouse tissues in other studies, including lung $\mathrm{CD}_{103}{ }^{+} \mathrm{T}_{\mathrm{RM}}$ primed by IAV infection. ${ }^{7,29}$ Interestingly, nearly one-quarter (23\%; 16 of the 69 genes) of the genes identified as uniquely regulated in $\mathrm{CD} 4 \mathrm{~T}_{\mathrm{RM}}$ overlap with the gene signature found to distinguish CD8 $\mathrm{T}_{\mathrm{RM}}$ from conventional memory CD8 T cells (Table 1). Functional annotation clustering analysis of these 16 shared genes revealed a 12 -fold enrichment in the "GTPase regulator and activator" pathway $(P$-value 0.003$)$ while those genes unique to $\mathrm{CD}^{+} \mathrm{T}_{\mathrm{RM}}$ clustered in the "cell adhesion" pathway ( $P$-value 0.009$)$. Remarkably, the CD4 $\mathrm{T}_{\mathrm{RM}}$ isolated from mice treated with
IL-2-neutralizing Ab shared preferential expression of 15 of these 16 genes (see Supplementary Table SII). This analysis suggests that a key set of signature $\mathrm{T}_{\mathrm{RM}}$ genes, perhaps involved in maintenance or function, are shared between CD4 and CD8 $\mathrm{T}_{\mathrm{RM}}$ subsets and between CD4 $\mathrm{T}_{\mathrm{RM}}$ generated by IL-2dependent and -independent pathways but that distinct cellular interactions in the lung may support the retention of $\mathrm{CD}^{+}$vs. $\mathrm{CD}^{+} \mathrm{T}_{\mathrm{RM}}$.

\section{CD4 $\mathrm{T}_{\mathrm{RM}}$ are functionally specialized and protective}

The unique gene expression by $\mathrm{CD} 4 \mathrm{~T}_{\mathrm{RM}}$ compared with conventional memory CD $4 \mathrm{~T}$ cells suggests that the $\mathrm{T}_{\mathrm{RM}}$ may possess distinct functional qualities. To evaluate their respective functions, we first compared the cytokine production potential of the IL-2-dependent and -independent $\mathrm{T}_{\mathrm{RM}}$ with that of conventional i.v. ${ }^{\text {labeled }}$ memory cells. The $\mathrm{T}_{\mathrm{RM}}$ generated in the presence or absence of IL-2 contained similar frequencies of interferon (IFN) $\gamma^{+}$and dual IFN- $\gamma^{+} / \mathrm{IL}-2^{+}$cells that were significantly greater than that of the conventional memory cells (Figure 3a-c). This enhanced potential to produce IFN- $\gamma$ suggests that the $\mathrm{T}_{\mathrm{RM}}$ may be better able to mediate protective responses against IAV, some of which depend on IFN $-\gamma^{31}$

We have previously shown that memory CD4 T cells isolated from the spleen and dLN of IAV-primed mice can protect otherwise naive mice against a lethal dose of IAV upon adoptive transfer. ${ }^{31}$ To test whether the $\mathrm{CD} 4 \mathrm{~T}_{\mathrm{RM}}$ are also protective, we isolated donor cells from lungs of IAV-primed mice that were treated with IL-2-neutralizing Abs (in which all of the donor cells fit criteria of $\mathrm{T}_{\mathrm{RM}}$ ) and transferred them to new hosts. The "take" of $\mathrm{T}_{\mathrm{RM}}$ was poor when the cells were transferred i.v. as compared with the recovery of an equal number of i.v. labeled memory cells (Figure 3d), a result similar to that seen in studies of adoptive transfer of $\mathrm{CD} 8 \mathrm{~T}_{\mathrm{RM}}$ cells that reported limited survival of $\mathrm{T}_{\mathrm{RM}}$ when introduced into the circulation. ${ }^{32}$ Furthermore, those $\mathrm{T}_{\mathrm{RM}}$ that could be re-isolated were largely confined to the lung vs. the i.v. ${ }^{\text {labeled }}$ donors that were found predominantly in the spleen (Figure 3e). We thus transferred the $T_{R M}$ using the intranasal (i.n.) route. The "take" of $T_{R M}$ in the lung 1 day following i.n. transfer was about $3 \%$, resulting in about $7.1 \times 10^{4}\left( \pm 1.07 \times 10^{4}\right)$ cells detected in the lungs after the transfer of $2.5 \times 10^{6}$ donor $\mathrm{T}_{\mathrm{RM}}$. No donor cells were detected in the spleen or dLN. This number of lung donor cells is in line with the physiological number of donor $\mathrm{T}_{\mathrm{RM}}$ detected in IAV-primed mice at $28 \mathrm{dpi}$ (see Figure 1). When the mice were challenged with a lethal dose of A/PR8-OVA ${ }_{\mathrm{II}}$, recipients of $4 \times 10^{6}$ or $2.5 \times 10^{6} \mathrm{~T}_{\mathrm{RM}}$ were protected while recipients of $1 \times 10^{6}$ cells did not survive (Figure 3f). Protection mediated by the $T_{R M}$ was associated with dramatically reduced viral titers vs. those detected in control animals, which all succumbed to infection (Figure 3g, left). Protection mediated by $\mathrm{T}_{\mathrm{RM}}$ transfer was also antigen dependent as the OVA-specific OT-II $\mathrm{T}_{\mathrm{RM}}$ do not reduce viral titers in mice challenged with PR8 (lacking $\mathrm{OVA}_{\text {II }}$ peptide expression; Figure 3g, right).

The earliest and perhaps most crucial function of CD4 $\mathrm{T}_{\mathrm{RM}}$ in orchestrating protective responses is likely their ability to rapidly induce the production of inflammatory cytokines and 
a<smiles>[C+]1CCCCC1</smiles>

\begin{tabular}{ll}
\multicolumn{2}{c}{ Log signal intensity } \\
Probe Set ID & Gene symbol \\
1419083_at & Tnfsf11 \\
1422706_at & Pmepa1 \\
1452794_X_at & 4933402 N22Rik \\
1448261_at & Cdh1 \\
1420150_at & Spsb1 \\
1416039_x_at & Cyr61 \\
1426037_a_at & Rgs16 \\
1428834_at & Dusp4 \\
1422705_at & Pmepa1 \\
1421854_at & Fgl2 \\
1433920_at & Sema4c \\
1417601_at & Rgs1 \\
1416303_at & Litaf \\
1438054_X_at & Ppp2r2c \\
1434735_at & Hif \\
1451601_a_at & Spns2 \\
1452123_s_at & Frmd4b \\
1444426_at & Cass4 \\
1456225_x_at & Trib3 \\
1435913_at & B4galnt4 \\
1416271_at & Perp \\
1425255_s_at & Hnrpll \\
1418114_at & Rbpj \\
1448294_at & Litaf \\
1449990_at & II2 \\
143311 _at & Cep170b
\end{tabular}

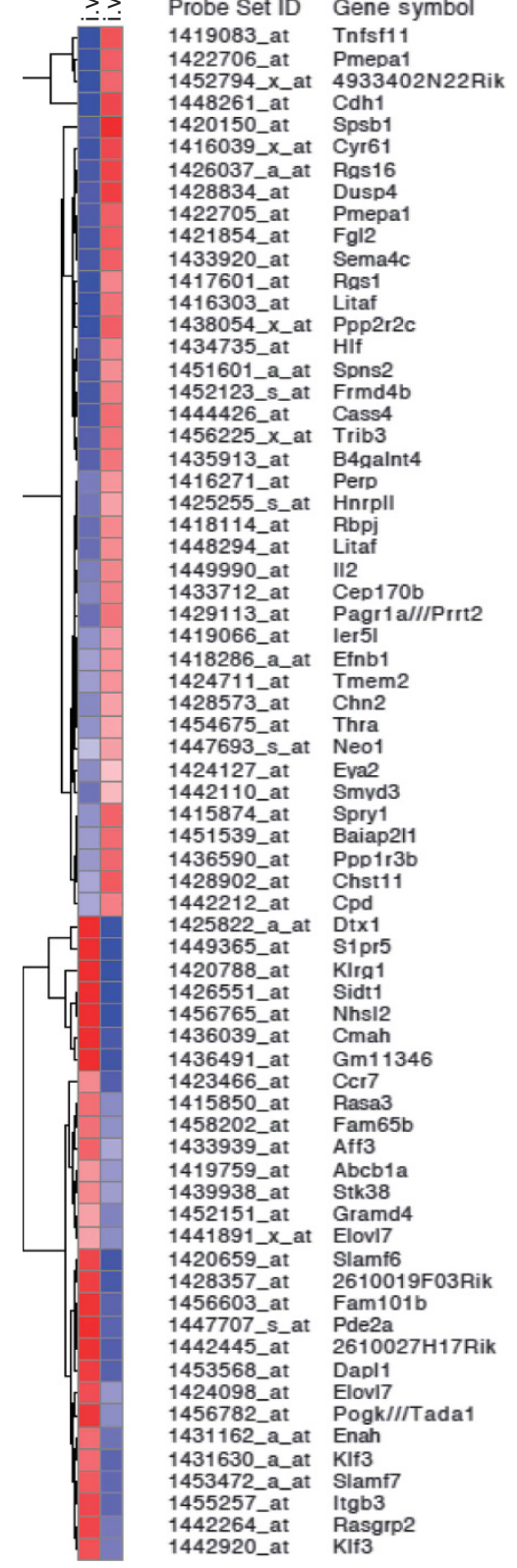

c

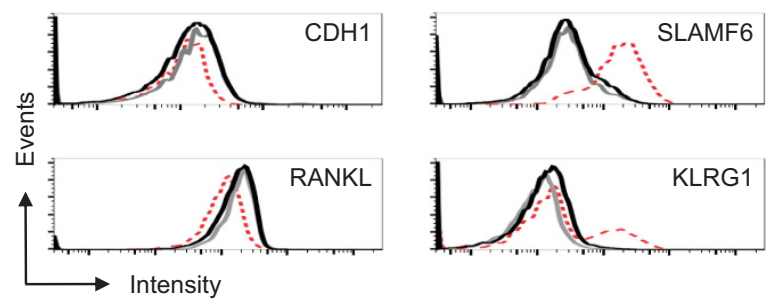

c
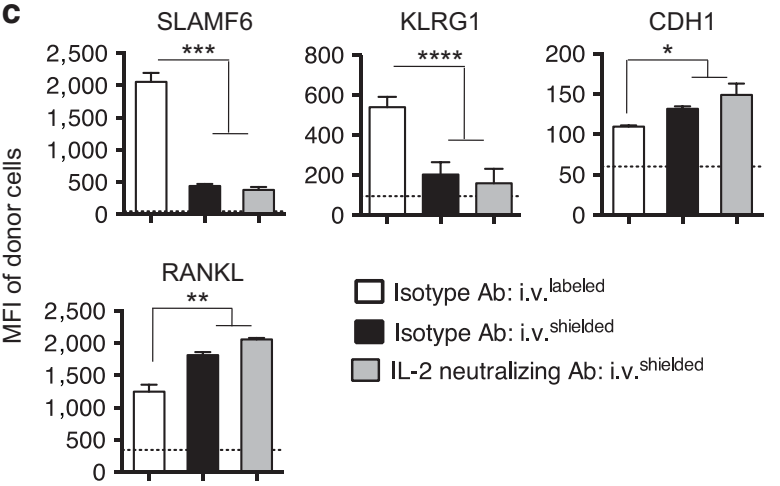

d

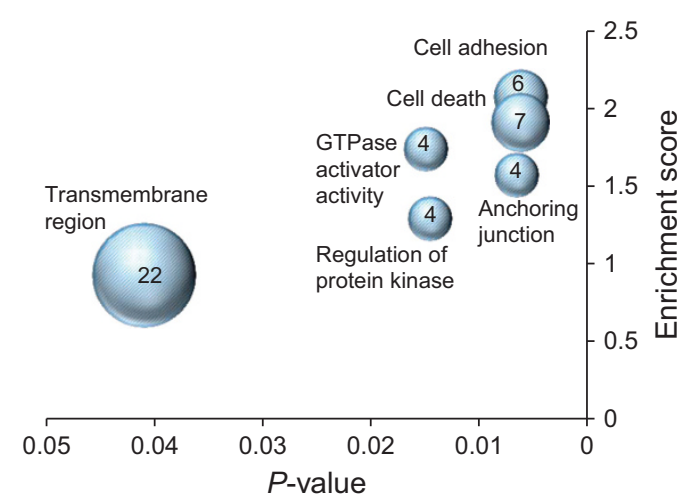

Figure 2 CD4 tissue-resident memory T cells express a unique transcriptional signature. OT-II cells were sort-purified from influenza A virus-primed hosts at 28 days postinfection. Whole-genome microarray was performed comparing i.v. shielded lung donor cells to i.v. labeled donor cells obtained from the lung and spleen. (a) Summary of genes differentially expressed by i.v. ${ }^{\text {shielded }}$ and i.v. ${ }^{\text {labeled }}$ donor cells at a threshold of $>1.5$-fold and $P$-value of 0.05 . (b) Representative staining of validation of differential surface marker expression from stated subsets and (c) mean fluorescence intensity (MFI) analysis from three mice per group (dotted line in bar graphs represent FMO control staining for each marker; one of the three independent experiments). (d) DAVID functional annotation analysis was performed on the genes summarized in Supplementary Table SI online that were differentially expressed by i.v. ${ }^{\text {shielded }}$ and i.v. ${ }^{\text {labeled }}$ donor cells. The most significantly enriched pathways $(P$-value of 0.05$)$ as well as the number of genes in each pathway are shown. $\mathrm{Ab}$, antibody.

chemokines in the tissue site. Indeed, very low numbers of memory CD4 T cells in the lung mediate control of IAV titers prior to the influx of other adaptive immune cells by jumpstarting inflammatory responses from DCs. ${ }^{33,34}$ To evaluate the role of $\mathrm{T}_{\mathrm{RM}}$ in this function, we first compared the ability of sortpurified OT-II $\mathrm{T}_{\mathrm{RM}}$ cells to activate bone marrow-derived DCs pulsed with $\mathrm{OVA}_{\text {II }}$ peptide in vitro vs. an equal number of i.v. ${ }^{\text {labeled }}$ OT-II memory cells isolated from the spleen. Both $\mathrm{T}_{\mathrm{RM}}$ and splenic memory cells similarly activated DCs to upregulate expression of CD40, CD86, and major histocompatibility complex-II by $40 \mathrm{~h}$ of culture (Figure 4a). However, significantly higher levels of several cytokines and 
Table 1 Genes differentially expressed by lung CD4 ${ }^{+} \mathrm{T}_{\mathrm{RM}}$ generated by IAV challenge and published CD103 ${ }^{+} \mathrm{CD8}^{+} \mathrm{T}_{\mathrm{RM}}$ from various models and tissues

\begin{tabular}{|c|c|c|c|}
\hline Gene & Product & $\uparrow / \downarrow \mathrm{T}_{\mathrm{RM}}$ & Reference \\
\hline Chn2 & Chimerin 2 & $\uparrow$ in $T_{R M}$ & 7 \\
\hline Rgs1 & Regulator of G-protein signaling 1 & $\uparrow$ in $T_{R M}$ & 7 \\
\hline Rgs16 & Regulator of G-protein signaling 16 & $\uparrow$ in $\mathrm{T}_{\mathrm{RM}}$ & 29 \\
\hline Elovi7 & ELOVL family member 7 , elongation of long chain fatty acids & $\downarrow$ in $T_{R M}$ & 7 \\
\hline Fam65b & Family with sequence similarity 65, member $B$ & $\downarrow$ in $T_{R M}$ & 7 \\
\hline Rasgrp2 & RAS, guanyl releasing protein 2 & $\downarrow$ in $T_{R M}$ & 7 \\
\hline S1pr5 & Shingosine 1-phosphate receptor 5 & $\downarrow$ in $T_{R M}$ & 7 \\
\hline Sidt1 & SID1 transmembrane family, member 1 & $\downarrow$ in $T_{R M}$ & 7,29 \\
\hline Ccr7 & C-C chemokine receptor type 7 & $\downarrow$ in $T_{R M}$ & 29 \\
\hline Dtx1 & Protein deltex-1 & $\downarrow$ in $T_{R M}$ & 29 \\
\hline
\end{tabular}

IAV, influenza A virus; $T_{\mathrm{RM}}$, tissue-resident memory T cells.

chemokines that we have previously correlated with protective inflammatory responses against IAV ${ }^{33}$ were detected in cocultures containing $\mathrm{T}_{\mathrm{RM}}$ (Figure $\mathbf{4 b}$ ).

We next asked whether enhanced inflammatory responses from DCs could be detected at early time points post-IAV challenge in the lungs of recipients of polyclonal CD4 $\mathrm{T}_{\mathrm{RM}}$. For these experiments, we sort-purified bulk i.v. ${ }^{\text {shielded }} \mathrm{CD} 4 \mathrm{~T}$ cells from IAV-primed mice at $28 \mathrm{dpi}$ and transferred $5 \times 10^{5}$ i.n. to new hosts that were then primed with IAV. We observed more IL- $6^{+}$and IL- $12^{+} \mathrm{CD} 11 \mathrm{c}^{+}$cells at 4 dpi in recipients of $\mathrm{T}_{\mathrm{RM}}$ (Figure 4c), as well as higher numbers of natural killer cells and neutrophils (Figure 4d,e). These results indicate the rapid initiation of local inflammatory responses by $\mathrm{T}_{\mathrm{RM}}$ following IAV challenge involving multiple innate immune populations.

\section{IL-15 is required to generate but not maintain IL-2-independent $T_{\mathrm{RM}}$}

Finally, we sought to determine whether an alternative cytokine signal is required for the generation of CD4 $\mathrm{T}_{\mathrm{RM}}$ through the IL2 -independent pathway. Given that IL-15 can support a degree of CD4 memory formation in some situations, ${ }^{35}$ we analyzed IL-15 expression following IAV challenge. We found that IL-15 protein in the lungs steadily increased during the first week of infection (Figure 5a), which is consistent with previous studies analyzing gene expression. ${ }^{36}$ In contrast, no IL-15 above background was detected in the serum (Figure 5a). The strong lung-restricted detection of IL-15 in response to IAV challenge suggests that it could be a central factor regulating $\mathrm{CD} 4{ }^{+} \mathrm{T}_{\mathrm{RM}}$ generation.

To determine whether IL-15 can support CD4 $\mathrm{T}_{\mathrm{RM}}$ generation, we first treated mice receiving donor cells with IL-2-neutralizing $\mathrm{Ab}$ alone, thus restricting donor fate to $\mathrm{T}_{\mathrm{RM}}$
(Figure 1), or with IL-2-neutralizing Ab in conjunction with a blocking Ab against CD122 (IL2/IL-15 receptor $\beta$ chain) from 1 to 7 dpi. Blocking CD122 efficiently disrupts IL-15 signals in vivo, ${ }^{37-39}$ and because IL-2 is neutralized in these experiments, any impact of CD122 blockade can clearly be attributed to an impact on IL-15 and not IL-2 signaling. Efficient CD122 blockade was verified by fluorescence-activated cell sorter at 7 dpi on cells responding in the lungs (Figure $\mathbf{5 b}, \mathbf{c}$ ). The addition of anti-CD122 Ab did not reduce peak effector accumulation at 7 dpi (Figure 5d), consistent with reports that IL-15 does not affect CD4 T-cell expansion during IAV challenge. ${ }^{40}$ Strikingly, in mice treated with CD122 blocking and IL-2-neutralizing Abs, virtually no donor cells could be recovered at $28 \mathrm{dpi}$ (Figure 5d), suggesting that the IL-2-independent $\mathrm{T}_{\mathrm{RM}}$ pathway requires IL-15. To confirm this finding, and to rule out a depleting effect of the CD122 blocking Ab, we transferred OT-II cells to wild-type (WT) or $I l 15^{-1-}$ B6 mice, challenged with IAV, and treated all hosts with IL-2neutralizing $\mathrm{Ab}$ from 1 to $7 \mathrm{dpi}$. No differences in peak donor expansion were seen at $7 \mathrm{dpi}$ in WT or $I l 15^{-/-}$hosts, but donor cells were virtually absent in $I l 15^{-/-}$hosts at $28 \mathrm{dpi}$, while $\mathrm{T}_{\mathrm{RM}}$ were readily detected in WT hosts (Figure 5e). Together, these results demonstrate the generation of a CD4 $\mathrm{T}_{\mathrm{RM}}$ subset in the lung through an IL-2-independent pathway that requires critical IL-15 signals during the first week of infection.

We next asked whether the IL-15 signals needed to generate the $\mathrm{CD} 4 \mathrm{~T}_{\mathrm{RM}}$ must be delivered through trans-presentation or if the CD4 T cells themselves need to express IL-15r $\alpha$ in order to mediate direct IL-15 signaling. To test this, we used WT $\left(\mathrm{CD} 90.1^{+} / \mathrm{CD} 90.2^{+}\right)$and conditional $I L 15 \mathrm{ra}^{-/-}\left(\mathrm{CD} 90.1^{+}\right)$ OT-II cells transferred to the same or seperate WT $\left(\mathrm{CD} 45.1^{+}\right)$ 
a

(-) Stimulation

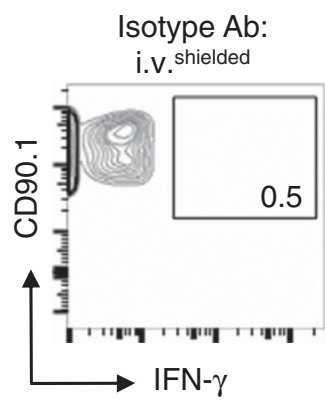

(+) Stimulation
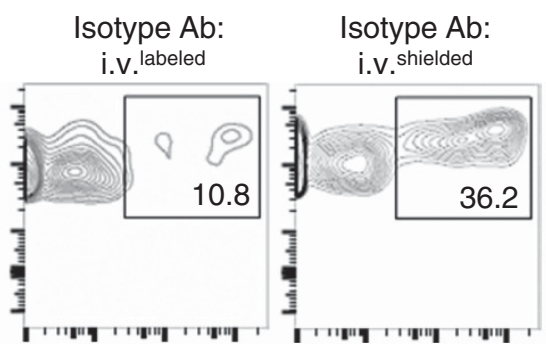

IL-2 neutralizing $A b$ : i.v. shielded

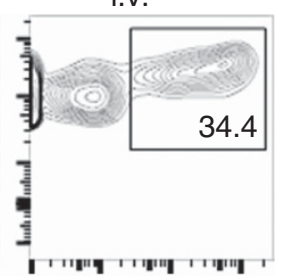

b

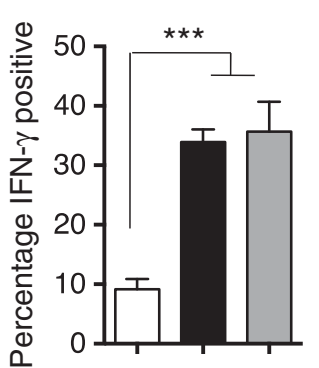

Isotype Ab: i.v. labeled

Isotype Ab: i.v. shielded

IL-2 neutralizing Ab: i.v. ${ }^{\text {shielded }}$

c

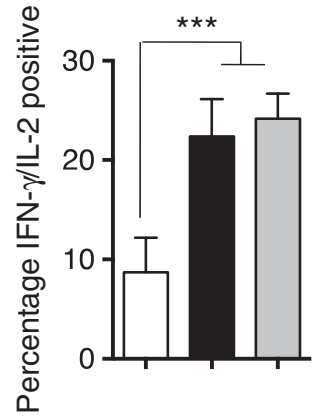

d

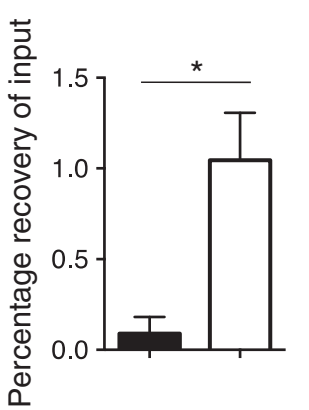

Lung donor

Spleen donor e

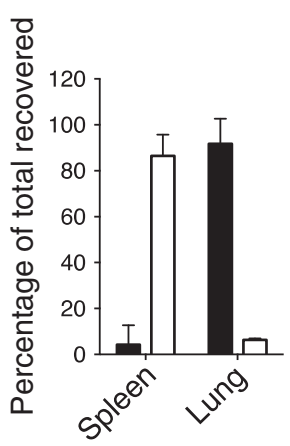

f

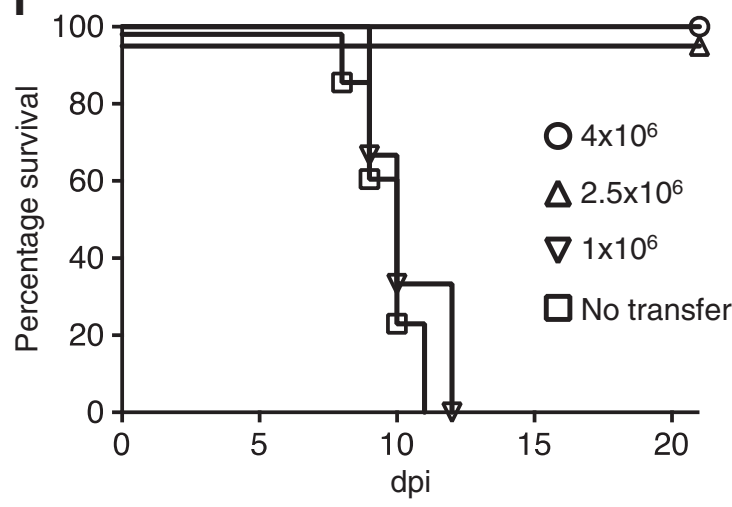

g

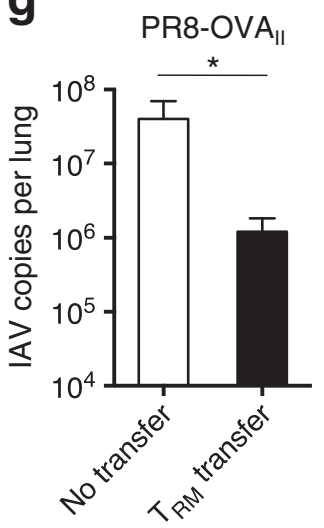

PR8

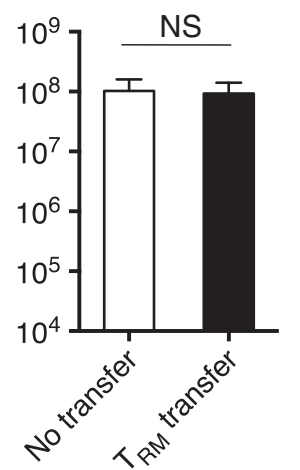

Figure 3 CD4 tissue-resident memory $T$ cells $\left(T_{R M}\right)$ display enhanced cytokine production capacity vs. conventional memory cells. At 28 days postinfection, donor cells in the lungs of influenza A virus (IAV)-primed mice were assessed for their ability to produce cytokines based on labeling with intravenous (i.v.) administered fluorescent CD4 antibody (Ab). (a) Representative staining of unstimulated (upper row) or stimulated i.v. labeled and i.v. ${ }^{\text {shielded }}$ donor cells (gated on Thy $1.1^{+}$cells) for interferon (IFN)- $\gamma$ and summary of the frequency of (b) IFN $\gamma$-producing and (c) dual IFN- $\gamma$ and IL-2producing donor cells from three mice per group (one of the three experiments). An equal number of donor $\mathrm{T}_{\mathrm{RM}}$ or splenic i.v. ${ }^{\text {labeled }}$ donor cells sort-purified from IAV-primed mice were transferred i.v. to new hosts in the absence of IAV infection. After 7 days, the total number of donor cells recovered from the spleen and lungs of adoptive hosts was determined. Shown is (d) the percentage of either donor population recovered relative to input and (e) the percentage of total donor cells recovered from either spleens or lungs of adoptive hosts (four mice per group). Donor $\mathrm{T}_{\mathrm{RM}}$ isolated from IAV-primed mice and $5 \times 10^{6}, 2.5 \times 10^{6}$, or $1 \times 10^{6}$ were transferred intranasally to unprimed mice followed by challenge with a lethal dose of PR8-OVA mice receiving $T_{\mathrm{RM}}$ vs. no transfer controls is shown (combined results from three separate experiments with three mice per group). (g) The viral titer from mice receiving $2.5 \times 10^{6}$ donor (OT-II) $\mathrm{T}_{\mathrm{RM}}$ or not and challenged with either PR8-OVA (left) or PR8 (right) (3-4 mice per group). NS, not significant.

mice that were challenged with IAV and treated to block IL-2 from 1 to $7 \mathrm{dpi}$. Whether co-transferred or transferred to different hosts, the number of WT and IL15ra ${ }^{-/}$- donors was similar at $7 \mathrm{dpi}$, but at $28 \mathrm{dpi}$ WT cells significantly outnumbered the $\mathrm{ILIFra}^{-/-}$donors (Figure 5f-h). This implies that effector cells require direct IL-15 signals within the first week of IAV infection to generate an IL-2-independent subset of CD4 $\mathrm{T}_{\mathrm{RM}}$.

Finally, we sought to determine whether, in addition to being required for the initial generation of the $\mathrm{T}_{\mathrm{RM}}$, IL-15 was also 
a

a $\quad \operatorname{CD} 40$
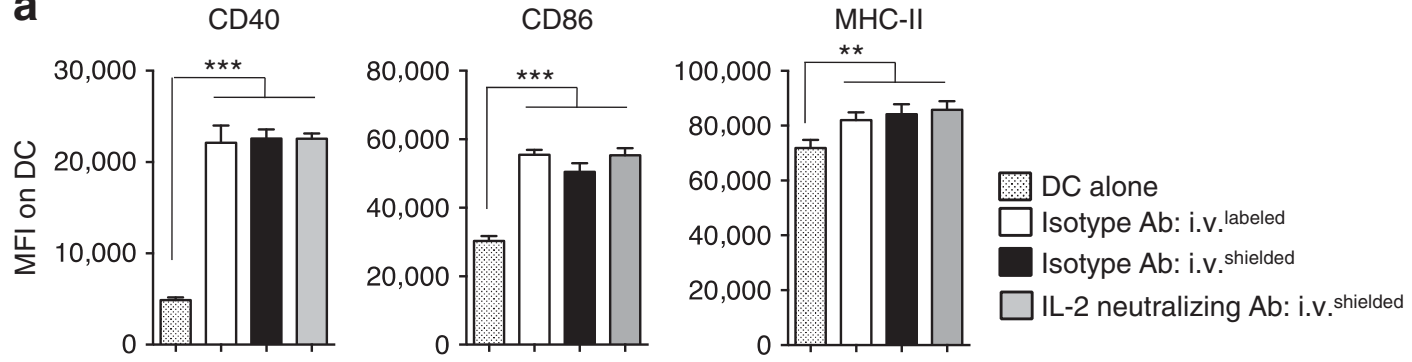

b
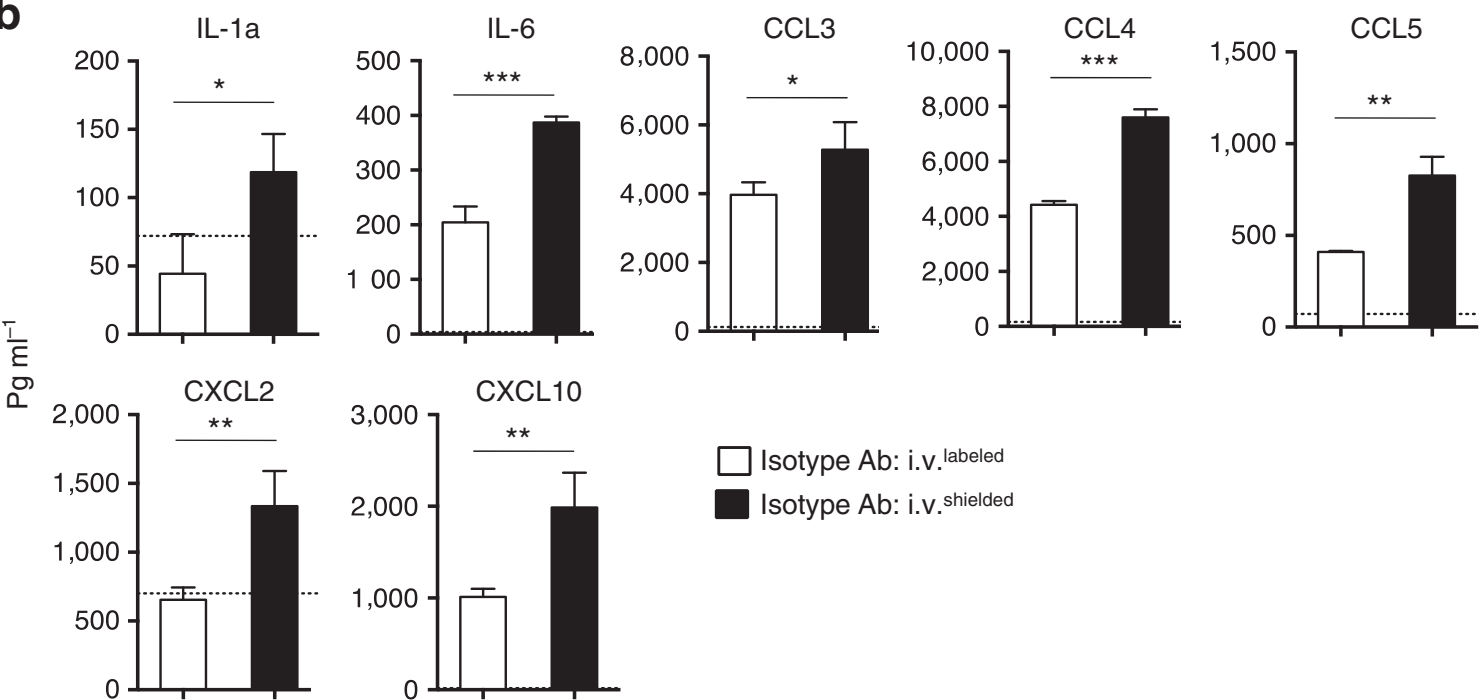

C

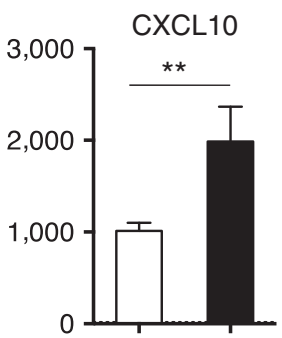

$\square$ Isotype $A b$ : i.v. ${ }^{\text {labeled }}$

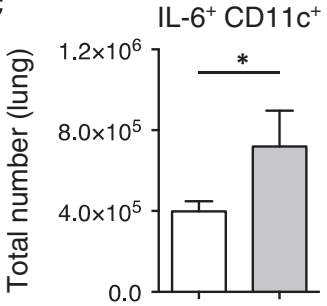

$\mathrm{IL}-12^{+} \mathrm{CD} 11 \mathrm{c}^{+}$

d
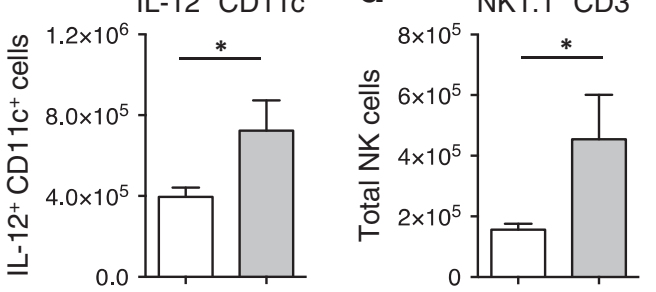

e

$\mathrm{CD}_{11 \mathrm{~b}} \mathrm{Gr}^{-1^{+}}$

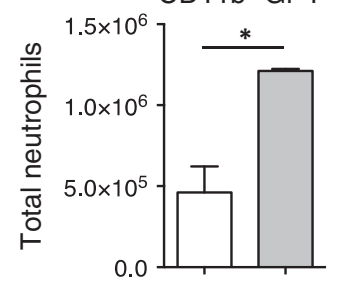

No transfer

Polyclonal i.v. ${ }^{\text {shielded }}$ CD4 cells

Figure 4 Lung tissue-resident memory T cells induce a more rapid inflammatory response from dendritic cells (DCs) than conventional memory CD4 T cells. Donor memory cells, $1 \times 10^{5}$, sort-purified from the lungs or spleens of influenza A virus (IAV)-primed mice on the basis of their ability to be labeled by CD4 Ab administered intravenously (i.v.) were cultured with an equal number of bone marrow-derived DC pulsed with OVA DCs were analyzed for the expression of molecules associated with their activation (triplicate conditions; one of the two experiments). (b) Supernatants from cultures of DCs and memory cells were harvested at $40 \mathrm{~h}$ and analyzed for stated cytokines and chemokines by luminex. Dotted lines indicate the average level detected in supernatants from wells containing DC and peptide alone (triplicate conditions; one of the two experiments). Sort-purified polyclonal i.v. ${ }^{\text {shielded }} \mathrm{CD} 4 \mathrm{~T}$ cells from the lungs of IAV-primed mice were transferred to unprimed mice followed by PR8 challenge. At 4 days postinfection, lungs were harvested and analyzed for the presence of (c) IL- $6^{+}$and IL- $12^{+}$CD11C ${ }^{+}$cells, (d) natural killer (NK) cells, and (e) neutrophils and compared with mice not receiving donor cells (3-4 mice per group; 1 of the 2 experiments). Ab, antibody; CXCL, C-X-C motif chemokine ligand; MHC, major histocompatibility complex.

required for the long-term maintenance of this subset. We thus transferred donor cells to mice that were challenged with IAV and treated with IL-2-neutralizing Ab from 1 to 7 dpi. Beginning on day 14 postinfection, coinciding with viral clearance in this model, mice were treated with CD122-blocking Ab or an isotype control every second day up to $28 \mathrm{dpi}$ and the presence of donor $\mathrm{T}_{\mathrm{RM}}$ analyzed on $30 \mathrm{dpi}$. Although treatment with CD122blocking $\mathrm{Ab}$ dramatically reduced the number of natural killer cells detected in the spleen (Figure 5i), a population known to be dependent on IL-15 for maintenance, ${ }^{41}$ the number of donor $\mathrm{T}_{\mathrm{RM}}$ was equivalent in mice treated with control vs. CD122blocking Ab (Figure 5j). These results indicate that, while IL-15 signals received within the first week of infection support the development of lung CD4 $\mathrm{T}_{\mathrm{RM}}$, continuous IL-15 signals are not required for the survival of this subset. This requirement for IL-15 during the first week of infection is similar to the 


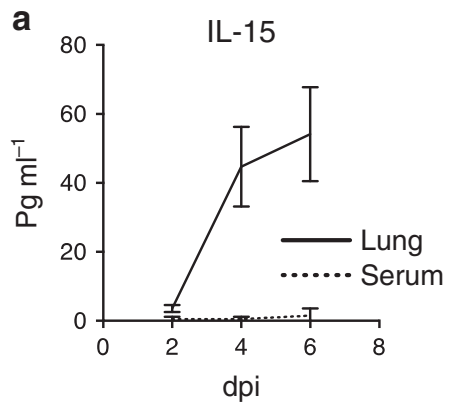

b

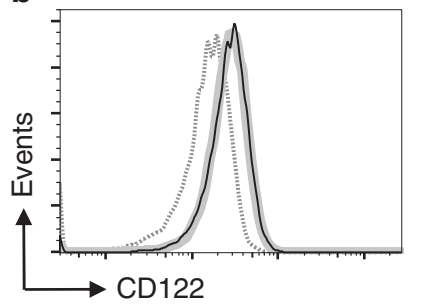

Isotype Ab

$\square \square$ IL-2 neutralizing Ab

....... $\square$ IL-2 neutralizing Ab + CD122 blocking Ab

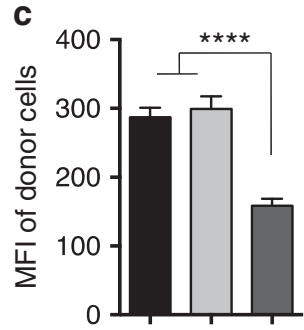

d

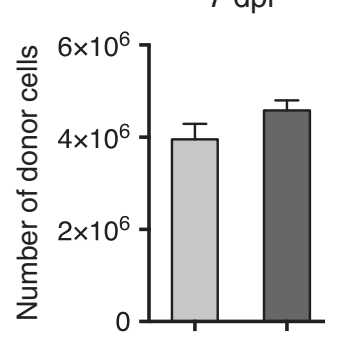

$28 \mathrm{dpi}$

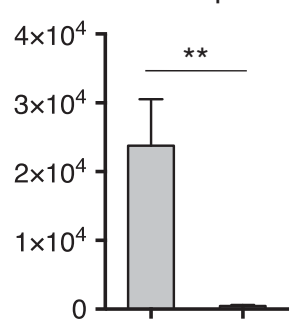

e

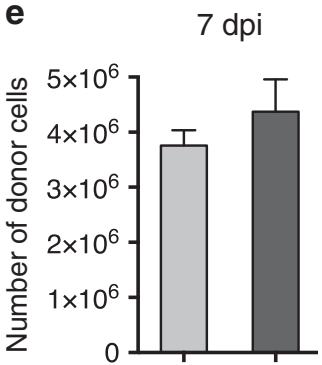

IL-2 neutralizing $A b+$ isotype

IL-2 neutralizing Ab + CD122 blocking Ab

f

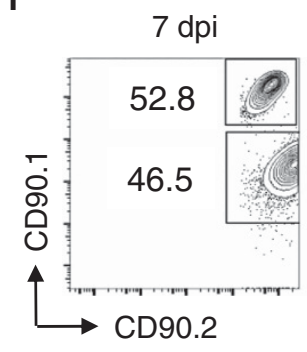

$28 \mathrm{dpi}$

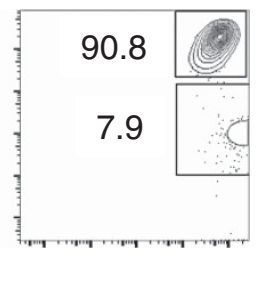

g

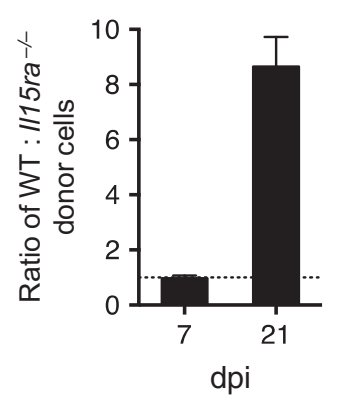

IL-2 neutralizing Ab: WT host

IL-2 neutralizing Ab: $/ 115^{-/-}$host

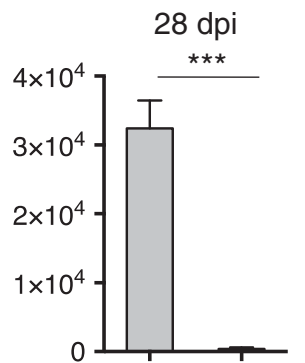

h
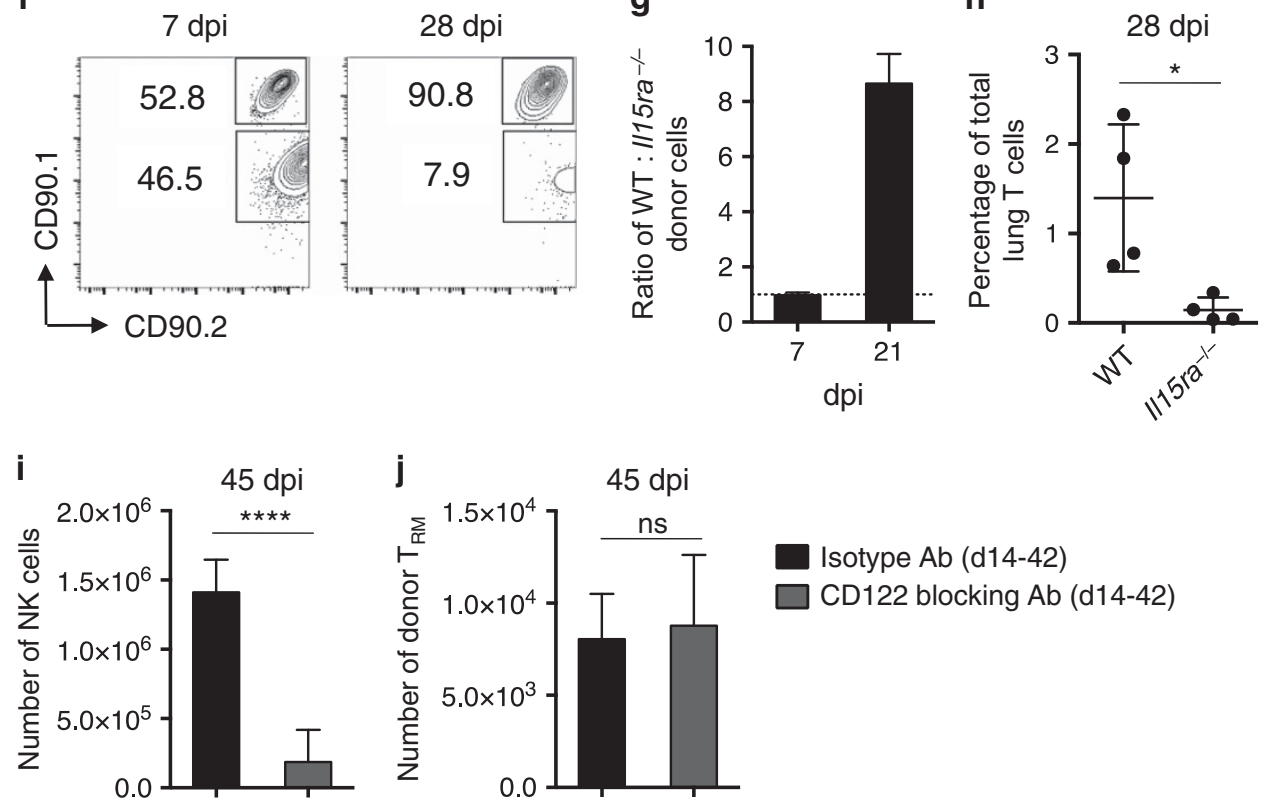

Isotype Ab (d14-42)

CD122 blocking Ab (d14-42)

Figure 5 Interleukin (IL)-15 is required for the generation of lung CD4 tissue-resident memory $\mathrm{T}_{\text {cells }}$ ( $\mathrm{T}_{\mathrm{RM}}$ ). (a) Lung homogenate and serum was analyzed from influenza A virus (IAV)-primed mice on stated days for the presence of IL-15 protein (four mice per group; one of the four experiments). Mice receiving donor cells and IAV priming were treated either with IL-2-neutralizing antibody (Ab) alone or with IL-2-neutralizing Ab and CD122-blocking Abs from 1 to 7 days postinfection (dpi). (b, c) On 7 dpi, donor cells in the lungs were analyzed for the expression of CD122 (representative from one of the four mice; one of the three similar experiments). (d) The number of donor cells present in the lung at 7 and $28 \mathrm{dpi}$ in mice treated as in a is shown (four mice per group). Donor cells were transferred to either wild-type (WT) or $/ / 15^{-/-}$hosts that were then primed with IAV and treated with IL-2-neutralizing Ab from 1 to $7 \mathrm{dpi}$. (e) Donor cells in the lung were enumerated at 7 and $28 \mathrm{dpi}$ (three mice per group; one of the three experiments). WT (Thy $1.1 /$ Thy 1.2$)$ and $/ / 15 r^{-} /$

- OT-II cells (Thy1.2) were transferred to WT CD45.1 ${ }^{+}$hosts that were primed with IAV and treated with IL-2-neutralizing Ab. (f) Representative staining for both donor populations at 7 and $28 \mathrm{dpi}$ and (g) the ratio of WT : //15ra ${ }^{-/}$- donor cells detected when co-transferred at 7 and $28 \mathrm{dpi}$ and (h) the recovery of WT vs. I/15ra $\mathrm{ra}^{-/}$donor cells when transferred to seperate hosts at $28 \mathrm{dpi}$ (four mice per group; one of the two experiments). Mice receiving WT donor cells and challenged with IAV were treated with IL-2-neutralizing Abs from 1 to 7 dpi and with CD122-blocking Ab or an isotype control every second day from 14 to $44 \mathrm{dpi}$. (i) The number of natural killer (NK) cells recovered from the spleens of mice and (j) the number of donor $\mathrm{T}_{\mathrm{RM}}$ recovered from the lung at 45 dpi was determined from 4 mice per group ( 1 of the 2 experiments). 
requirement for IL-2 during the first week of infection to form the IL-2-dependent $\mathrm{T}_{\mathrm{RM}}$ subset and supports the concept that these are alternate but parallel pathways.

\section{DISCUSSION}

We previously found that autocrine IL-2 signaling of CD4 T cells, which is induced by cognate antigen recognition, is needed during the effector stage of IAV infection to generate virtually all memory cells present in secondary lymphoid organs. The IL-2 prevents acute death of effector cells during the contraction phase and enhances their fitness to access IL-7 by upregulating sustained CD127 expression. ${ }^{16,17}$ Here we show that IL-2 signals also support the generation of a subset of CD4 $\mathrm{T}_{\mathrm{RM}}$ in the lung, which is consistent with findings of IL-2dependent lung $\mathrm{T}_{\mathrm{RM}}$ in an asthma model. ${ }^{42}$ However, we also describe a novel IL-2-independent pathway in which direct IL15 signals received by CD4 effector cells supports the generation of a separate but similar cohort of long-lived, highly functional and protective CD4 $\mathrm{T}_{\mathrm{RM}}$ in the lung. As IL-2 and IL- 15 both signal through the same CD122 receptor and downstream adaptor molecules, some of their respective impacts in promoting $\mathrm{CD} 4^{+}$memory formation are likely similar. For example, similar to IL-2, IL-15 can mediate acute antiapoptotic effects in activated CD4 $\mathrm{T}$ cells in vitro. ${ }^{43}$ However, treatment with subsaturating levels of IL-2 and IL-15 drives unique gene expression in T cells. ${ }^{44}$ This suggests that key elements of the IL-15-dependent program promoting CD4 $\mathrm{T}_{\mathrm{RM}}$ are likely distinct from the IL-2-dependent pathway, a hypothesis supported by the IL-7-independent survival of the IL-2-independent CD4 $\mathrm{T}_{\mathrm{RM}}$.

The remarkable degree of overlap in gene expression patterns distinguishing CD4 $\mathrm{T}_{\mathrm{RM}}$ in this study and $\mathrm{CD} 8^{+} \mathrm{T}_{\mathrm{RM}}$ in other studies including those induced by similar IAV infection ${ }^{7,29}$ is notable. This suggests that a conserved molecular program supports the maintenance and function of all $\mathrm{T}_{\mathrm{RM}}$ (CD4 and CD8) in non-lymphoid tissues. The prominence of genes differentially expressed by both $\mathrm{CD}^{+}$and $\mathrm{CD}^{+}{ }^{+} \mathrm{T}_{\mathrm{RM}}$ associated with GTPase activity suggests a central role for these proteins in $\mathrm{T}_{\mathrm{RM}}$ homeostasis, possibly through regulating cell shape as indicated by studies of skin CD8 $\mathrm{T}_{\mathrm{RM}} \cdot{ }^{45,46}$ On the other hand, that the genes we identified as uniquely expressed by lung $\mathrm{CD}^{+} \mathrm{T}_{\mathrm{RM}}$ were most enriched in cell adhesion pathways supports the hypothesis that different $\mathrm{T}_{\mathrm{RM}}$ subsets (i.e. $\mathrm{CD}^{+}$and $\mathrm{CD} 8{ }^{+}$) within the same tissue may employ distinct mechanisms for local retention, perhaps indicating their residence in unique microenvironments. Recently, Hombrink et al..$^{30}$ have demonstrated remarkable conservation of gene expression between lung-resident $\mathrm{CD} 8 \mathrm{~T}_{\mathrm{RM}}$ in mice and humans. Further studies are required to determine to what extent the $\mathrm{CD} 4 \mathrm{~T}_{\mathrm{RM}}$-specific gene expression patterns identified here translate into lung-resident human CD4 memory cells.

We found that the CD4 $\mathrm{T}_{\mathrm{RM}}$ mediate robust protection against lethal IAV infection when transferred back to the lung. $\mathrm{T}_{\mathrm{RM}}$-mediated protection correlated with accelerated inflammatory responses in the lung marked by increased production of cytokines from DCs and elevated numbers of innate cells. In previous studies, this "jump-start" of innate immunity by memory CD4 T cells correlated with early viral control, ${ }^{33,34}$ and we also saw impressive reduction of viral titers in recipients of CD4 $\mathrm{T}_{\mathrm{RM}}$. The rapid induction of inflammation likely also facilitates optimal CD8 T-cell trafficking by establishing early chemokine gradients ${ }^{47}$ and may help the response of other CD4 T-cell specificities during heterosubtypic challenge. ${ }^{48}$ Indeed, we found elevated levels of several chemokines in co-cultures of DCs and $\mathrm{T}_{\mathrm{RM}}$ compared with co-cultures with conventional memory cells. Although all of these are factors are known to be produced by DCs, further studies are required to determine if the $\mathrm{T}_{\mathrm{RM}}$ are also capable of specialized production of distinct chemokine signals. Our analysis suggests that the ability of CD4 $T_{R M}$ to induce enhanced inflammatory responses may be related to their expression of surface molecules known to impact antigen-presenting cell function. For example, we found that Slamf6, which can interfere with T-cell adhesion to DCs, ${ }^{49}$ to be expressed at lower levels by $\mathrm{T}_{\mathrm{RM}}$ than by conventional memory cells, and RANKL (receptor activator of nuclear factor- $\kappa B$ ligand; TRANCE, TNFSF11), which can deliver an adjuvant-like signal to DCs, ${ }^{50,51}$ to be expressed at higher levels by $\mathrm{T}_{\mathrm{RM}}$. It is important to point out that only minor differences in surface expression of RANKL, CDH1, and KLRG1, which may nevertheless be biologically significant, distinguish $T_{R M}$ and conventional memory cells. As such, these markers are not as suitable for distinguishing CD4 $\mathrm{T}_{\mathrm{RM}}$ and other memory subsets as are levels of CD127 and CD69. Further studies are needed to investigate the relative importance of these and other distinguishing attributes of $\mathrm{T}_{\mathrm{RM}}$ in contributing to their local retention, survival, and protective function.

IL-15 has been proposed to act as a local "alarm" in tissues that promotes maximal Th1 and CD8 T-cell responses needed to clear viral pathogens. ${ }^{52}$ Our findings provide support that this "alarm" can also act as a potent signal to induce long-lived CD4 $\mathrm{T}_{\mathrm{RM}}$. Although it is not clear from these studies that IL-15production is strictly limited to the lungs, the lung-restricted detection of IL-15 following IAV infection supports the concept that $\mathrm{T}_{\mathrm{RM}}$ generation is regulated through factors induced by infection at tissue sites. This is in sharp contrast to the CD4 T-cell-intrinsic autocrine IL-2 signals that are absolutely required to promote conventional memory $\mathrm{CD} 4 \mathrm{~T}$ cells primed by IAV ${ }^{16,17}$ and that also support a cohort of IAV-primed CD4 $\mathrm{T}_{\mathrm{RM}}$. Although our studies show near identical phenotype and function of the IL-2- and IL-15-dependent $\mathrm{T}_{\mathrm{RM}}$, further work is required to determine whether these subsets have distinct or overlapping roles in protective immunity upon reinfection. A recent study employing IL-15-adjuvanted vaccinia-based IAV vaccination found that memory $\mathrm{CD} 4^{+}$, but not $\mathrm{CD} 8{ }^{+}$, $\mathrm{T}$ cells had a predominant role in the protection generated..$^{53}$ Although $\mathrm{T}_{\mathrm{RM}}$ subsets were not assessed, the authors found CD4 T-cell responses in the lung were enhanced to a greater extent by IL-15 than those detected systemically. ${ }^{53}$ This suggests that the incorporation of IL-15 into vaccination formulations, or strategies that lead to its local production, might boost the generation of protective, functionally specialized CD4 $\mathrm{T}_{\mathrm{RM}}$ in the lung and perhaps other tissues. 


\section{METHODS}

Mice. C57BL/6 (Taconic (Hudson, New York) or Jackson Laboratories, Bar Harbor, ME), B6.CD45.1 (Jackson), and $I l 15^{-/-}$mice on a C57BL/6 background (Taconic) mice were at least 8 weeks old at the time of infection. Donor CD4 ${ }^{+} \mathrm{T}$ cells were obtained from 5-to-8week-old OT-II.Thyl.1 mice that express a TcR recognizing aa 323-339 (ISQAVHAAHAEINEAGR) of chicken ovalbumin (OVA). OT-II.Thy1.1 mice, originally from Jackson Laboratories, were bred at the University of Massachusetts Medical School or at the University of Central Florida. Nr4a1 ${ }^{\mathrm{eGFP}}$-expressing mice (Nur77 reporter mice) were originally obtained from Jackson Laboratories and used to breed Nr4a $1^{\text {eGFP }}$ OT-II donor mice. Il15ra ${ }^{f l}$ mice, possessing loxP sites flanking exons $2-3$ of the IL-15 receptor $\alpha$ chain (CD122) were obtained from Jackson Laboratories and bred to OT-II mice expressing Cre recombinase to generate conditional $\mathrm{Il}_{\mathrm{H}} \mathrm{ra}^{-/-}$OT-II mice. All experimental animal procedures were conducted in accordance with University of Massachusetts Medical School's and University of Central Florida's Animal Care and Use Committee guidelines.

CD4 T-cell isolation and cell transfer. Naive $\mathrm{CD} 4{ }^{+} \mathrm{T}$ cells from OTII mice were obtained from pooled spleen and lymph nodes. Single-cell suspensions were passed over nylon wool, followed by percoll gradient separation and positive MACS selection using CD4 microbeads (Miltenyi, Auburn, CA). Resulting cells were routinely $>97 \% \mathrm{TCR}^{+}$ and expressed a characteristic naive phenotype (small size, CD62 $\mathrm{L}^{\mathrm{hi}}$, $\mathrm{CD} 44^{\mathrm{lo}}$, and $\left.\mathrm{CD} 25^{\mathrm{lo}}\right)$. CD 4 T cells were cultured under Th1-polarizing conditions including exogenous IL-2 as previously described. ${ }^{16}$ The resulting effector cells were thoroughly washed and rested for at least 3 days in media free of antigen (Ag) from which live cells were purified by lympholyte separation (Cederlane, Burlington, NC). The resting, IL-2-primed donor cells were adoptively transferred to unprimed mice in $200 \mu \mathrm{l}$ phosphate-buffered saline (PBS) by i.v. injection.

Donor CD4 T cells expressing CD90.1 were re-isolated from the lungs of IAV-primed CD90.2 B6 mice by first digesting and homogenizing lungs using GentleMACS (Miltenyi) followed by positive selection using MACS for CD90.1. The purity of donor cells was confirmed by fluorescence-activated cell sorter and $1-4 \times 10^{6}$ cells transferred i.n. to unprimed $\mathrm{B} 6$ hosts. In other experiments, CD4 ${ }^{+}$ i.v. ${ }^{\text {shielded }}$ cells were obtained from the lungs of donor B6 mice by cell sorting followed by i.n. transfer of $5 \times 10^{5}$ cells to unprimed recipients.

Viral infection and in vivo treatments. $\mathrm{A} / \mathrm{PR} 8$ and $\mathrm{A} / \mathrm{PR} 8-\mathrm{OVA}_{\mathrm{II}}$ (H1N1) (kindly provided by P. Doherty) was grown in the allantoic cavity of embryonated hen eggs and characterized at the Trudeau Institute. Mice were infected i.n. under light isoflurane anesthesia (Webster Veterinary Supply, Ocala, FL) with a sublethal $\left(0.1 \mathrm{LD}_{50}\right)$ dose in $50 \mu \mathrm{PBS}$. Mice received adoptively transferred T cells in $200 \mu \mathrm{l}$ of serum-free media via i.v. or retro-orbital injection and were infected on the same day.

In some experiments, mice were treated with $250 \mu \mathrm{g}$ per day of the anti-IL-2 Abs S4B6 and JES6-1A12 (Rat IgG2a) from 1 to 7 dpi or with appropriate isotype control Ab (all from BioXcell, West Lebanon, NH). Some mice receiving anti-IL-2 Ab treatment were also given $250 \mu \mathrm{g}$ of anti-CD122 Ab clone TM- $\beta 1$ or isotype control (Rat IgG2b) from 1 to $7 \mathrm{dpi}$ or an isotype control (Bioxcell). In other experiments, mice were treated with an IL-7 receptor-blocking Ab clone A7R34 (Bioxcell). All $\mathrm{Ab}$ was administered by i.p. injection in $200 \mu \mathrm{l}$ of PBS.

In some experiments, IAV-primed mice were treated for 5 consecutive days with $2.5 \mathrm{mg} \mathrm{kg}^{-1}$ of FTY720 (Cayman Chemical, Ann Arbor, MI) dissolved in water by i.p. injection.

In vivo fluorescent $A b$ labeling, tissue preparation, and cell isolation. Anesthetized mice were injected i.v. with $3 \mu \mathrm{g}$ of APClabeled anti-CD4 Ab in $100 \mu \mathrm{l}$ of PBS and killed 3-4 min later by cervical dislocation followed by exsanguination by perforation of the abdominal aorta. Lungs were perfused by injecting $10 \mathrm{ml}$ of PBS in the left ventricle of the heart. Lungs, spleen, and dLNs were prepared into single-cell suspensions by mechanical disruption of organs and passage through a nylon membrane or by enzymatic digestion using
GentleMACS (Miltenyi). In some experiments, donor cells from the lung or spleen were isolated using cell sorting based on the expression of Thy1.1, CD69 and the i.v. administered APC-labeled anti-CD4 Ab.

Flow cytometry and intracellular cytokine staining. Flow cytometry was performed using fluorochrome-labeled Abs for surface staining anti-CD90.1 (OX-7), anti-CD90.2 (53-2.1), anti-CD4 (RM4.5), anti-CD69 (H12F3), anti-CD127 (A7R34), anti-CD122 (TM- $\beta 1)$, antiCD103 (B-Ly7), anti-KLRG1 (2F1), anti-CDH1 (DECMA-1), antiSLAMF6 (13G3-19D), anti-RANKL (IK22/5), anti-CD40 (1C10), anti-CD86 (GL1), anti-major histocompatibility complex-II (M5/ 114.15.2), anti-CD11c (HL3), anti-NK1.1 (PK136), anti-CD11b (M1/ 70), and anti-CD3 (17A2) (BD Biosciences, San Jose, CA, eBioscience, San Diego, CA, or BioLegend, San Diego, CA). Intracellular cytokine staining was performed by stimulating cells for $16 \mathrm{~h}$ with $\mathrm{OVA}_{\text {II }}$ peptidepulsed APC. After $2 \mathrm{~h}, 10 \mu \mathrm{g} \mathrm{ml}^{-1}$ Brefeldin A (Sigma, St. Louis, MO) was added, and after a further $2 \mathrm{~h}$, the cells were surface stained and fixed for $20 \mathrm{~min}$ in $4 \%$ paraformaldehyde. Intracellular staining was performed by permeabilizing the cells for $10 \mathrm{~min}$ in $0.1 \%$ saponin before staining for cytokine by the addition of anti-IFN- $\gamma$ (XMG1.2), anti-IL-2 (JES-5H4), anti-IL-6 (MP5-20F3), anti-IL-10 (JES-16E3), anti-IL-12 (C17.8), and anti-IL-17 (eBio17B7) fluorescently labeled Abs. Analysis was performed using LSRII or Canto II instruments (BD Biosciences) and FlowJo (Tree Star, Ashland, OR) analysis software.

T-cell and DC co-culture and detection of cytokines and chemokines. Sort-purified OT-II memory cells from the lung $\left(\mathrm{CD} 69^{+}\right.$ i.v..$^{\text {shielded }}$ ) or spleen $\left(\mathrm{CD} 69^{\text {low }}\right.$ i.v. $\left.{ }^{\text {labeled }}\right) 0.5 \times 10^{5}$ per well were cocultured in vitro in Costar 24-well plates (Corning, Corning, NY) in the absence or presence of $\mathrm{OVA}_{\text {II }}$ peptide with $1 \times 10^{5}$ syngeneic bone marrow-derived DCs prepared as previously described. ${ }^{9}$ Levels of cytokines and chemokines in triplicate culture supernatants were determined using a Mouse Multi-Plex Luminex Kit (Millipore, Burlington, MA) read on a Luminex 200 reader (Luminex, Austin, TX). Luminex analysis was similarly used to detect IL-15 protein from lung homogenates and serum samples.

Microarray analysis. Prior to harvest, mice receiving donor cells and IAV challenge 28 days prior were administered fluorescently labeled anti-CD4 i.v. and the spleens and lungs harvested 3-5 min later. Donor cells were isolated by first enzymatically digesting the tissues using GentleMACS (Miltenyi) followed by cell sorting based on Thy expression (gating on donor Thy marker) and CD69 (used as a confirmatory marker for $\mathrm{T}_{\mathrm{RM}}$ in the lung).

Total mRNA was isolated (Qiagen, Hilden, Germany) and amplified (Ambion, Austin, TX) from sort-purified populations of OT-II memory cells isolated from the lungs or spleens of IAV-primed mice at 28 dpi. cRNAs were labeled and hybridized to M430 2.0 chips according to Affymetrix protocols in triplicate. Data were normalized with the Plier algorithm, log transformed, and analyzed with GeneSpring GX 11.0 (Agilent Technologies, Overland Park, KS). Significant genes were selected based on $P$-values $<0.05$ and fold change $>1.5$ after correction for false discovery.

Real-time PCR. Viral titers were determined by quantitation of viral RNA. RNA was prepared from whole lung homogenates using TRIzol (Sigma), and $2.5 \mu \mathrm{g}$ of RNA was reverse transcribed into cDNA using random hexamer primers and Superscript II Reverse Transcriptase (Invitrogen, Waltham, MA). Quantitative PCR was performed to amplify the polymerase (PA) gene of A/PR8-OVA ${ }_{I I}$ using an ABI Prism 7700 Sequence Detector (Applied Biosystems, Foster City, CA) with $50 \mathrm{ng}$ of cDNA per reaction and the following primers and probe: forward primer, $5^{\prime}$-CGGTCCAAATTCCTGCTGA-3'; reverse primer, $5^{\prime}$-CATTGGGTTCCTTCCATCCA-3'; and probe, 5'-6-FAMCCAAGTCATGAAGGAGAGGGAATACCGCT- $3^{\prime}$. Data were analyzed with Sequence Detector v1.7a (Applied Biosystems). The copy number of the PA gene per 50 ng of cDNA was calculated using a PA-containing plasmid of known concentration as a standard. 
Statistical analysis. Unpaired, two-tailed, Students $t$-tests, and $\alpha=0.05$ were used to assess whether the means of two normally distributed groups differed significantly. One-way analysis of variance with Bonferroni's multiple comparison posttest was employed to compare multiple means. All error bars represent the s.d. Significance is indicated as ${ }^{\star} P<0.05,{ }^{* *} P<0.005,{ }^{* *} P<0.001$, and ${ }^{\star * * *} P<0.0001$.

Data availability. Microarray data that support the findings of this study will be deposited in the Gene Expression Omnibus with accession number GSE105257.

SUPPLEMENTARY MATERIAL is linked to the online version of the paper at http://www.nature.com/mi

\section{ACKNOWLEDGMENTS}

We thank Dr Richard Dutton for helpful comments. We also thank Phyllis Spatrick of the UMASS Medical School Genomics Core Facility for assistance with RNA amplification and microarray analysis. This work was supported by National Institutes of Health Grants Al117457 (to T.M.S.), Al118820-01 (to S.L.S.), Al46530 (to S.L.S.), Al109858-02 (Project 2, to S.L.S.), American Heart Association grant 14SDG18600020 (to K.K.M.), the University of Massachusetts Medical School, and the University of Central Florida.

\section{AUTHOR CONTRIBUTIONS}

T.M.S., S.L.S., and K.K.M. designed experiments, analyzed data, and wrote the manuscript. T.M.S., K.D., C.F., J.H., C.C., and K.K.M. performed experiments.

\section{DISCLOSURE}

The authors declared no conflict of interest.

c) 2018 Society for Mucosal Immunology

\section{REFERENCES}

1. Swain, S.L., McKinstry, K.K. \& Strutt, T.M. Expanding roles for CD4(+) T cells in immunity to viruses. Nat. Rev. Immunol. 12, 136-148 (2012).

2. Mueller, S.N., Gebhardt, T., Carbone, F.R. \& Heath, W.R. Memory T cell subsets, migration patterns, and tissue residence. Annu. Rev. Immunol. 31, 137-161 (2013).

3. Strutt, T.M., McKinstry, K.K., Marshall, N.B., Vong, A.M., Dutton, R.W. \& Swain, S.L. Multipronged CD4(+) T-cell effector and memory responses cooperate to provide potent immunity against respiratory virus. Immunol. Rev. 255, 149-164 (2013).

4. Shin, H. \& Iwasaki, A. Tissue-resident memory Tcells. Immunol. Rev. 255, 165-181 (2013).

5. Bevan, M.J. Memory T cells as an occupying force. Eur. J. Immunol. 41, 1192-1195 (2011)

6. Mueller, S.N. \& Mackay, L.K. Tissue-resident memory T cells: local specialists in immune defence. Nat. Rev. Immunol. 16, 79-89 (2015).

7. Mackay, L.K. et al. The developmental pathway for CD103(+)CD8+ tissue-resident memory T cells of skin. Nat. Immunol. 14, 1294-1301 (2013).

8. Laidlaw, B.J. et al. CD4(+) Tcell help guides formation of CD103(+ ) lungresident memory $\mathrm{CD} 8(+)$ T cells during influenza viral infection. Immunity 41, 633-645 (2014).

9. Casey, K.A. et al. Antigen-independent differentiation and maintenance of effector-like resident memory T cells in tissues. J. Immunol. 188, 48664875 (2012)

10. Yu, C.I. et al. Human CD1C + dendritic cells drive the differentiation of CD103 + CD8 + mucosal effector T cells via the cytokine TGF-beta. Immunity 38, 818-830 (2013).

11. Sheridan, B.S., Pham, Q.M., Lee, Y.T., Cauley, L.S., Puddington, L. \& Lefrancois, L. Oral infection drives a distinct population of intestinal resident memory CD8(+) T cells with enhanced protective function. Immunity 40, 747-757 (2014).
12. El-Asady, R. et al. TGF-\{beta\}-dependent CD103 expression by CD8(+) T cells promotes selective destruction of the host intestinal epithelium during graft-versus-host disease. J. Exp. Med. 201, 1647-1657 (2005).

13. Wakim, L.M., Smith, J., Caminschi, I., Lahoud, M.H. \& Villadangos, J.A. Antibody-targeted vaccination to lung dendritic cells generates tissueresident memory CD8 T cells that are highly protective against influenza virus infection. Mucosal Immunol. 8, 1060-1071 (2015).

14. Turner, D.L. \& Farber, D.L. Mucosal resident memory CD4 T cells in protection and immunopathology. Front. Immunol. 5, 331 (2014).

15. Sathaliyawala, T. et al. Distribution and compartmentalization of human circulating and tissue-resident memory T cell subsets. Immunity $\mathbf{3 8}$, 187-197 (2012)

16. McKinstry, K.K. et al. Effector CD4 T-cell transition to memory requires late cognate interactions that induce autocrine IL-2. Nat. Commun. 5, 5377 (2014).

17. Bautista, B.L. et al. Short-lived antigen recognition but not viral infection at a defined checkpoint programs effector CD4 T cells to become protective memory. J. Immunol. 197, 3936-3949 (2016).

18. Thomas, P.G., Brown, S.A., Yue, W., So, J., Webby, R.J. \& Doherty, P.C. An unexpected antibody response to an engineered influenza virus modifies CD8 + T cell responses. Proc. Natl. Acad. Sci. USA 103, 2764-2769 (2006).

19. Anderson, K.G. \& Mayer-Barber, K. et al. Intravascular staining for discrimination of vascular and tissue leukocytes. Nat. Protoc. 9, 209-222 (2014).

20. Turner, D.L. et al. Lung niches for the generation and maintenance of tissue-resident memory T cells. Mucosal Immunol. 7, 501-510 (2014).

21. Wu, T. et al. Lung-resident memory CD8 Tcells (TRM) are indispensable for optimal cross-protection against pulmonary virus infection. J. Leukoc. Biol. 95, 215-224 (2014).

22. Park, C.O. \& Kupper, T.S. The emerging role of resident memory T cells in protective immunity and inflammatory disease. Nat. Med. 21, 688-697 (2015).

23. Mackay, L.K. et al. Cutting edge: CD69 interference with sphingosine-1phosphate receptor function regulates peripheral Tcell retention. J. Immunol. 194, 2059-2063 (2015).

24. Skon, C.N., Lee, J.Y., Anderson, K.G., Masopust, D., Hogquist, K.A. \& Jameson, S.C. Transcriptional downregulation of S1 pr1 is required for the establishment of resident memory CD8 + Tcells. Nat. Immunol. 14, 12851293 (2013).

25. Moran, A.E. et al. T cell receptor signal strength in Treg and iNKT cell development demonstrated by a novel fluorescent reporter mouse. J. Exp. Med. 208, 1279-1289 (2011).

26. Jelley-Gibbs, D.M., Brown, D.M., Dibble, J.P., Haynes, L., Eaton, S.M. \& Swain, S.L. Unexpected prolonged presentation of influenza antigens promotes CD4 T cell memory generation. J. Exp. Med. 202, 697-706 (2005).

27. Kondrack, R.M., Harbertson, J., Tan, J.T., McBreen, M.E., Surh, C.D. \& Bradley, L.M. Interleukin 7 regulates the survival and generation of memory CD4 cells. J. Exp. Med. 198, 1797-1806 (2003).

28. Brinkmann, V. et al. The immune modulator FTY720 targets sphingosine 1phosphate receptors. J. Biol. Chem. 277, 21453-21457 (2002).

29. Wakim, L.M. et al. The molecular signature of tissue resident memory CD8 T cells isolated from the brain. J. Immunol. 189, 3462-3471 2012).

30. Hombrink, P. et al. Programs for the persistence, vigilance and control of human CD8 + lung-resident memory T cells. Nat. Immunol. 17, 1467-1478 (2016).

31. McKinstry, K.K. et al. Memory CD4 + T cells protect against influenza through multiple synergizing mechanisms. J. Clin. Invest. 122, 2847-2856 (2012).

32. Wakim, L.M., Woodward-Davis, A. \& Bevan, M.J. Memory Tcells persisting within the brain after local infection show functional adaptations to their tissue of residence. Proc. Natl. Acad. Sci. USA 107, 17872-17879 (2010).

33. Strutt, T.M. et al. Memory CD4 + T cells induce innate responses independently of pathogen. Nat. Med. 16, 558-564 (2010). 1p following 564.

34. Chapman, T.J., Lambert, K. \& Topham, D.J. Rapid reactivation of extralymphoid CD4 T cells during secondary infection. PLOS ONE 6, e20493 (2011). 
35. Purton, J.F., Tan, J.T., Rubinstein, M.P., Kim, D.M., Sprent, J. \& Surh, C.D. Antiviral CD4 + memory T cells are IL-15 dependent. J. Exp. Med. 204, 951-961 (2007).

36. Verbist, K.C., Cole, C.J., Field, M.B. \& Klonowski, K.D. A role for IL-15 in the migration of effector CD8 T cells to the lung airways following influenza infection. J. Immunol. 186, 174-182 (2011).

37. Yokoyama, S. et al. Antibody-mediated blockade of IL-15 reverses the autoimmune intestinal damage in transgenic mice that overexpress IL-15 in enterocytes. Proc. Natl. Acad. Sci. USA 106, 15849-15854 (2009).

38. Richer, M.J., Pewe, L.L., Hancox, L.S., Hartwig, S.M., Varga, S.M. \& Harty, J.T. Inflammatory IL-15 is required for optimal memory Tcell responses. J. Clin. Invest. 125, 3477-3490 (2015).

39. Marcais, A. et al. The metabolic checkpoint kinase mTOR is essential for IL15 signaling during the development and activation of NK cells. Nat. Immunol. 15, 749-757 (2014).

40. Nakamura, R., Maeda, N., Shibata, K., Yamada, H., Kase, T. \& Yoshikai, Y. Interleukin-15 is critical in the pathogenesis of influenza a virus-induced acute lung injury. J. Virol. 84, 5574-5582 (2010).

41. Prlic, M., Blazar, B.R., Farrar, M.A. \& Jameson, S.C. In vivo survival and homeostatic proliferation of natural killer cells. J. Exp. Med. 197, 967-976 (2003).

42. Hondowicz, B.D. et al. Interleukin-2-dependent allergen-specific t issue-resident memory cells drive asthma. Immunity 44, 155-166 (2016).

43. Dooms, $H$. et al. Quiescence-inducing and antiapoptotic activities of IL-15 enhance secondary CD4 + T cell responsiveness to antigen. J. Immunol. 161, 2141-2150 (1998).
44. Ring, A.M. et al. Mechanistic and structural insight into the functional dichotomy between IL-2 and IL-15. Nat. Immunol. 13, 1187-1195 (2012).

45. Zhang, Q. et al. DOCK8 regulates lymphocyte shape integrity for skin antiviral immunity. J. Exp. Med. 211, 2549-2566 (2014).

46. Zaid, A. et al. Chemokine receptor-dependent control of skin tissueresident memory T cell formation. J. Immunol. 199, 2451-2459 (2017).

47. Teijaro, J.R., Verhoeven, D., Page, C.A., Turner, D. \& Farber, D.L. Memory CD4 T cells direct protective responses to influenza virus in the lungs through helper-independent mechanisms. J. Virol. 84, 9217-9226 (2010).

48. Olson, M.R. et al. Helping themselves: optimal virus-specific CD4 T cell responses require help via CD4 $\mathrm{T}$ cell licensing of dendritic cells. J. Immunol. 193, 5420-5433 (2014).

49. Chu, C. et al. SAP-regulated T cell-APC adhesion and ligation-dependent and -independent Ly108-CD3zeta interactions. J. Immunol. 193, 38603871 (2014).

50. Josien, R., Wong, B.R., Li, H.L., Steinman, R.M. \& Choi, Y. TRANCE, a TNF family member, is differentially expressed on $T$ cell subsets and induces cytokine production in dendritic cells. J. Immunol. 162, 2562-2568 (1999).

51. Josien, R. et al. TRANCE, a tumor necrosis factor family member, enhances the longevity and adjuvant properties of dendritic cells in vivo. J. Exp. Med. 191, 495-502 (2000).

52. Jabri, B. \& Abadie, V. IL-15 functions as a danger signal to regulate tissueresident T cells and tissue destruction. Nat. Rev. Immunol. 15, 771-783 (2015).

53. Valkenburg, S.A. et al. IL-15 adjuvanted multivalent vaccinia-based universal influenza vaccine requires CD4 + T cells for heterosubtypic protection. Proc. Natl. Acad. Sci. USA 111, 5676-5681 (2014). 